\title{
The thermal biology of fish in the Laurentian Great Lakes: insight from biologging and biotelemetry tools.
}

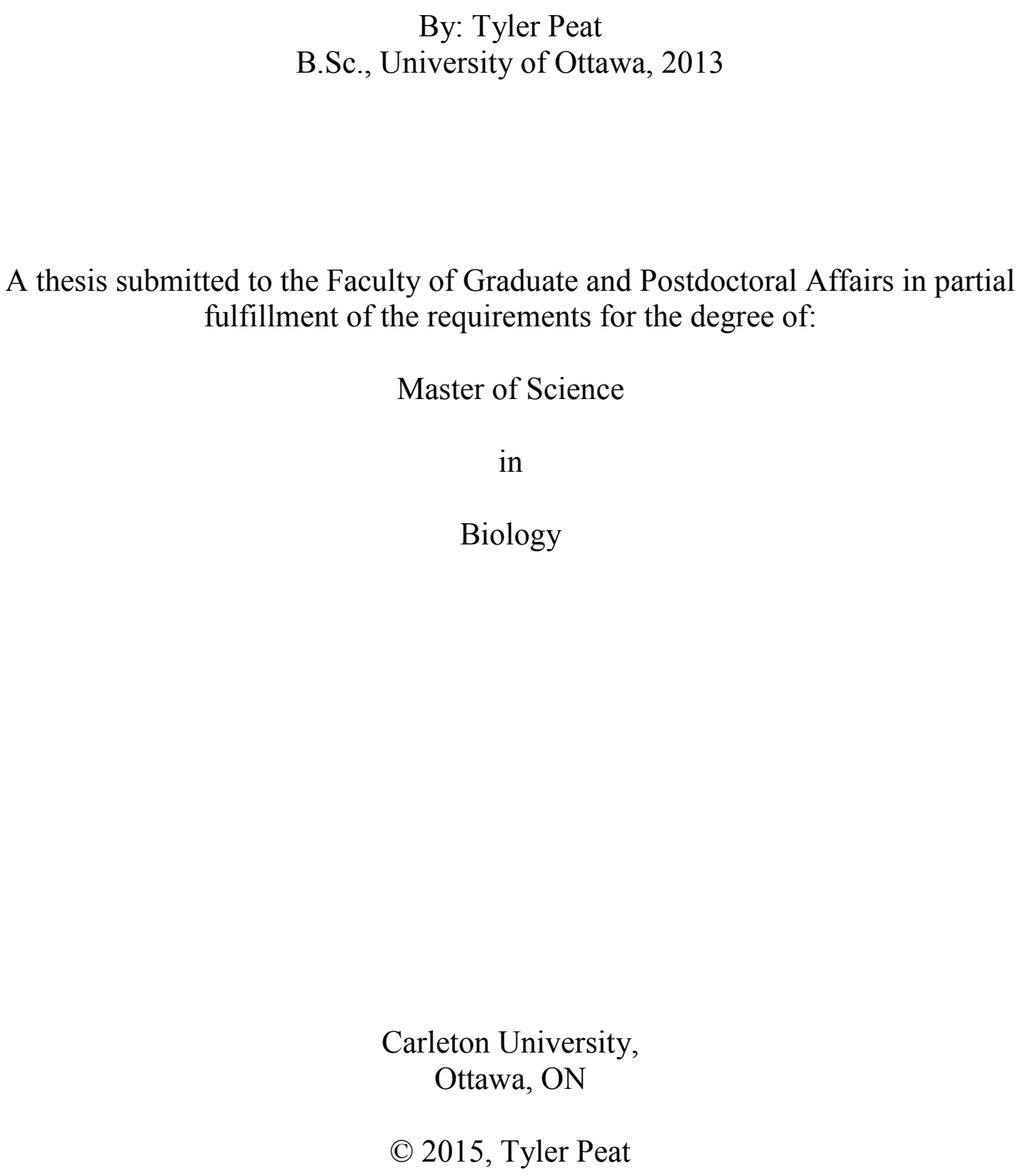

B.Sc., University of Ottawa, 2013

fulfillment of the requirements for the degree of:

Master of Science

in

Biology

Carleton University,

C 2015, Tyler Peat 


\begin{abstract}
Although the thermal biology of many freshwater species of fish is well known, the majority of this information has been determined in a laboratory setting, while information on thermal biology of free-swimming fish is rare. The purpose of this thesis was to characterize the thermal biology of three important fish species in the Laurentian Great Lakes using biologging and biotelemetry tools. Thermal patterns for adult walleye from Lake Erie and Huron were determined using biologging to assess the effects of sex, fish size, diel periods, and location (i.e., lake) using a generalized linear mixed model. Sex, size, and diel periods had no effect on thermal occupancy of adult walleye in either lake. Thermal occupancy differed between lakes and seasons. The depths and temperatures used by different sizes of northern pike and largemouth bass in the Toronto Harbour of Lake Ontario were studied using biotelemetry. Analyses of the data revealed northern pike occupied deeper depths, while experiencing similar thermal regimes throughout the majority of the year compared to largemouth bass, with the exception of summer, where pike were observed in cooler waters than bass. As water temperatures exceeded $10{ }^{\circ} \mathrm{C}$, both northern pike and largemouth bass were observed to behaviourally thermoregulate and selected temperatures warmer than those in the vicinity of the telemetry stations at which they were detected. When water temperatures exceeded 20 ${ }^{\circ} \mathrm{C}$, northern pike were observed to select cooler waters. As a whole, this thesis enhances the understanding of the thermal biology of free-swimming fish in the Laurentian Great Lakes informing the management of three economically, ecologically, and socially important fish species.
\end{abstract}




\section{Acknowledgements}

I would like to thank my supervisor, Dr. Steven Cooke, for providing me with the opportunity of obtaining a masters degree and for his continued assistance and support along the way. I would also like to thank all my co-authors, in particular Lee Gutowsky, Dr. John Dettmers, Dr. Todd Hayden, and Dr. Charles Krueger, for their much appreciated and valuable comments, as well as their assistance with data analysis. I thank Dr. Jon Midwood, Andrew Rous, Maxime Veilleux, Dr. Todd Hayden and Adam Weir, as well as the entire staff of the TRCA, Michigan DNR, and Ohio DNR for their help in the completion of all necessary fieldwork. Funding for my research was provided by Great Lakes Restoration Initiative appropriations (GL-00E23010-3), and by Natural Sciences and Engineering Research Council of Canada (NSERC) in the form of an NSERC Strategic Grant to Cooke and Wells and Discovery Grants to Cooke and Wells. Cooke is further supported by the Canada Research Chairs program. 


\section{Co-Authorship Statement}

\section{Chapter 2: The thermal biology of adult walleye (Sander vitreus) in Lakes Erie and Huron.}

Tyler B. Peat, Todd A. Hayden, Lee F. G. Gutowsky, Christopher S. Vandergoot, David G. Fielder, Charles P. Madenjian, Karen J. Murchie, John M. Dettmers, Charles C. Krueger, and Steven J. Cooke.

This manuscript has been submitted for review to the Journal of Thermal Biology. The project was conceived by Cooke, Dettmers, and Krueger. Field work was completed by Hayden. All analyses were conducted by Peat, and modelling by Gutowsky. All coauthors provided feedback on the manuscript.

\section{Chapter 3: Comparative thermal biology of northern pike (Esox lucius)} and largemouth bass (Micropterus salmoides) in nearshore environments of Lake Ontario

Tyler B. Peat, Lee F. G. Gutowsky, Susan E. Doka, Jon D. Midwood, Nicholas W.R. Lapointe, Bogdan Hlevca, Mathew G. Wells, Rick Portiss, Steven J. Cooke

This manuscript is in preparation for submission to Ecology of Freshwater Fish. The project was conceived by Cooke, and Midwood. Fieldword was completed by Peat, Lapointe, Midwood, and Hlevca. All analyses were conducted by Peat, and modelling by Gutowsky. All co-authors provided feedback on the manuscript. 


\section{Table of Contents}

Abstract ii

Acknowledgements iii

Co-Authorship Statement iv

Table of Contents $\quad$ v

List of Tables $\quad$ vi

List of Figures $\quad$ vii

Chapter 1. General Introduction 1

Chapter 2. The thermal biology of adult walleye (Sander vitreus) in Lakes Erie and Huron.

2.1 Abstract 4

2.2 Introduction 5

$\begin{array}{ll}2.3 \text { Methods } & 7\end{array}$

$\begin{array}{ll}2.4 \text { Results } & 12\end{array}$

$\begin{array}{ll}2.5 \text { Discussion } & 14\end{array}$

2.6 Chapter 2 Acknowledgements 23

$\begin{array}{lr}2.7 \text { Tables } & 24\end{array}$

$\begin{array}{lr}2.8 \text { Figures } & 27\end{array}$

Chapter 3. Comparative thermal biology of northern pike (Esox lucius) and largemouth bass (Micropterus salmoides) in nearshore environments of Lake Ontario.

3.1 Abstract

3.2 Introduction

3.3 Methods $\quad 35$

3.4 Results $\quad 42$

3.5 Discussion 45

3.6 Chapter 3 Acknowledgements

3.7 Tables $\quad 53$

$\begin{array}{lr}3.8 \text { Figures } & 58\end{array}$

Chapter 4. General Discussion $\quad 65$

$\begin{array}{lr}\text { References } & 68\end{array}$ 


\section{List of Tables}

Table 2.7.1: Summary of physical attributes (e.g., sex, number of individuals, length, and age) and days at liberty after tagging of adult walleye (Sander vitreus) caught by the Lake Erie and Lake Huron fisheries as of October of 2013. Days at liberty refer to the time individual walleye spent in each lake before being caught.

Table 2.7.2: The importance of fixed terms, variance covariate $(\beta)$, and correlation structure (Month|Fish ID) for our model predicting the thermal experience of walleye (Sander vitreus) in Lake Erie and Lake Huron. The approximate significance of the smoother (Month) for Lake Erie was $\left(\mathrm{F}_{8.231}=95.72, \mathrm{P}<0.0001\right)$ and for Lake Huron $\left(\mathrm{F}_{8.240}=209.0, \mathrm{P}<0.0001\right)$. Length, sex, size, diel period, were all insignificant in our model $(\mathrm{P}>0.025)$.

Table 2.7.3: Results of one-way ANOVA and Tukey's range test applied to accumulated thermal units (ATUs) for walleye (Sander vitreus) from the following three Lake Huron subpopulations: (1) those fish migrating to northern Lake Huron, (2) those fish remaining in Saginaw Bay, and (3) those fish migrating to southern Lake Huron.

Table 3.7.1: Summary of physical attributes (e.g., sex, length, weight) of tagged largemouth bass and northern pike in the Toronto Harbour as of January 2014. In total 83 largemouth bass and 74 northern pike of various sizes were caught and tagged with either Vemco V9TP or V13TP acoustic tags.

Table 3.7.2: Summary of the average seasonal temperatures $\left({ }^{\circ} \mathrm{C}\right)$ and depths $(\mathrm{m})$ of largemouth bass and northern pike recorded in the Toronto Harbour from April 2011 through to January 2014. N represents the total number of observation for each species, $\mathrm{SD}$ represents the standard deviation, and SE represents the standard error.

Table 3.7.3: Summary statistics calculated from data on the depths and temperatures largemouth bass and northern pike were observed at in the Toronto Harbour, Toronto, Ontario, Canada. Included is the average minimums, $1^{\text {st }}$ quartile, median, $3^{\text {rd }}$ quartile, and average maximums.

Table 3.7.4: Mean body and water temperatures $\left({ }^{\circ} \mathrm{C}\right)$ of largemouth bass and northern pike in the Toronto Harbour. Differences are between body temperature and the corresponding water temperature of the station at which each observation was detected. Negative values represent periods here the body temperature of fish was less than that of the water temperatures. Shown are observations for when water temperatures were greater then $10{ }^{\circ} \mathrm{C}$, and when water temperatures were greater than $20{ }^{\circ} \mathrm{C}$. N represents the total number of observations for each species.

Table 3.7.5: Model selection statistics from GLMMs on the Log Temperature and Log Depth of tagged Largemouth Bass and Northern Pike in the Toronto Harbour, ON. K is the number of parameters; AICc is the bias-corrected Akaike Information Criterion; $\triangle \mathrm{AICc}$ is the difference in bias-corrected AIC between a given model and the top ranked model; wAICc is the relative weight of the bias-corrected AIC; CumulWt is the cumulative Akaike weights and; L-Lik is the log-likelihood of the models. All models 
contain individual fish ID as a random intercept. Models are fitted with an additional variance structure to allow for different variances for each stratum of Season. 


\section{List of Figures}

Figure 2.8.1. Collection sites for adult walleye (Sander vitreus) for Lake Erie (Orleans Park, Maumee River) and Lake Huron (Dow Dam, Tittabawassee River). Red dots represent the locations of individual VR2W acoustic telemetry receivers positioned in Lake Erie, Lake Huron, and along the Huron-Erie corridor, which includes the St. Clair River, Lake St. Clair, and the Detroit River.

Figure 2.8.2. Thermal data for walleye (Sander vitreus) mean maximum seasonal temperatures (panel a), mean seasonal temperatures (panel b), and mean minimum seasonal temperatures (panel c) for both Lake Erie (labeled LE) and Lake Huron (labeled LH) individuals. Asterisks represent significant differences between lakes within seasons $(\mathrm{P}<0.05)$. The horizontal lines represent the means of each group. Whiskers represent the largest and smallest observations within each group that fall within 1.5x of the interquartile range. Observations that exceed this interquartile range are plotted as open circles. Mean maximum and minimum values for each lake were determined by averaging the highest and lowest of temperatures experienced by individual walleye during each season.

Figure 2.8.3: Example thermal profiles typifying two female adult walleye (Sander vitreus) from Lake Erie and Lake Huron (panels A and C respectively), and two male adult walleye (Sander vitreus) from Lake Erie and Lake Huron (panels B and D respectively). Shaded areas represent the $95 \%$ confidence intervals.

Figure 2.8.4: Predicted temperatures experienced by adult walleye (Sander vitreus) in Lake Huron (A) and Lake Erie (B) throughout the course of a year, with dashed lines representing the $95 \%$ confidence intervals. Values for predicted temperatures of each lake were obtained using a generalized additive mixed model.

Figure 2.8.5: Box and whisker plot of the accumulated thermal units (ATUs) of walleye (Sander vitreus) who migrate north, remain in Saginaw Bay, or migrate south. The horizontal lines represent the means of each group. Whiskers represent the largest and smallest observations within each group that fall within $1.5 \mathrm{x}$ of the interquartile range. Observations that exceed this interquartile range are plotted as open circles. Different letters are representative of significant differences between groups.

Figure 3.8.1. Map of study area and positions of acoustic receiver arrays in the Toronto Harbour. Deployment years range between 2010 and 2013, and are specified by the different sizes of filled and open circles for each station. Stations that are still currently deployed are enclosed with a larger open circle.

Figure 3.8.2. Water temperatures of the Toronto Harbour from October 2011 through April 2013. Temperatures were recorded every 4 hours daily by HOBO temperature loggers fixed at reciever stations. Panel A represents temperatures taken from Cherry Beach; panel B represents temperatures taken from Cell 2; Panel C represents temperatures taken from Cell 3; panel D represents temperatures taken from the Toronto Island; panel $\mathrm{E}$ represnts temperatures taken from Embayment $\mathrm{A}$; panel $\mathrm{F}$ represents temperatures taken from Embayment $\mathrm{C}$; panel $\mathrm{G}$ represents temperatures taken from 
Embayment D; panel $\mathrm{H}$ represents temperatures taken from Lake Ontario; and panel I represnts temperatures taken from Outer Harbour Marina.

Figure 3.8.3. Seasonal thermal data and depth data for largemouth bass (panels A and C respectively) and northern pike (panels $\mathrm{B}$ and $\mathrm{D}$ respectively) present in the Toronto Harbour, Toronto, Ontario, Canada. The horizontal lines represent the means of each group. Whiskers represent the largest and smallest observations within each group that fall within $1.5 \mathrm{x}$ of the interquartile range. Observations that exceed this interquartile range are plotted as open circles.

Figure 3.8.4. Relative amount of time spent within specific ranges of temperatures for tagged northern pike (A) and largemouth bass (B). Presented is a histogram paired with a kernal density estimation (dotted line), which estimates the likelihood of a random variable (e.g., Temperature) to take on a given value. Shaded regions represent optimal temperatures for growth of each species, and the arrow represents the minimum temperatures needed for growth to occur for each species.

Figure 3.8.5. Largemouth bass (A) and northern pike (B) temperatures versus water temperatures in the Toronto Harbour, Toronto, Ontario, Canada. Plotted is a smoothed condition mean, and its 95\% confidence intervals (shaded areas). The dashed line repsents the point at which water temperature is equal to fish temperature.

Figure 3.8.6. Mean fitted values for Northern Pike (E. lucius) and Largemouth Bass ( $M$. salmoides) temperature use $\left({ }^{\circ} \mathrm{C} \pm 95 \% \mathrm{CI}\right)$ in the Toronto Harbour, Toronto, Ontario, Canada. Body sizes are illustrated as circle (small, minimum - 25\% quartile), triangle (moderate, 25\% - 75\% quartile), and square (large, 75\% - maximum) symbols.

Figure 3.8.7. Mean fitted values for northern pike (E. lucius) and largemouth bass $(M$. salmoides) depth use $(\mathrm{m} \pm 95 \% \mathrm{CI})$ in the Toronto Harbour, Toronto, Ontario, Canada. Body sizes are illustrated as circle (small, minimum - 25\% quartile), triangle (moderate, $25 \%-75 \%$ quartile), and square (large, $75 \%$ - maximum) symbols. 


\section{Chapter 1 - General Introduction}

Temperature has been described as a characteristic of an organism's habitat (Magnuson et al. 1979), and is referred to as the most important environmental factor for aquatic species, influencing virtually all physiological, biochemical and life-history processes (Brett 1971). Temperature is known as a dynamic factor, and is constantly fluctuating on a diel and seasonal basis. Since most fish species are poikilothermic, the internal temperature of fish closely reflects that of the surrounding water temperature. Beitinger et al. (2000) attributed this conformity to a number of anatomical and physiological factors (i.e. high specific heat of water, low metabolic rates, absence of insulation, and countercurrent lamellar blood-water flow). At thermal equilibrium, the temperature of a fish is typically less than $1{ }^{\circ} \mathrm{C}$ above the water temperature (Spigarelli et al. 1977). As such, understanding the thermal biology of an organism is imperative when attempting to describe or monitor an individual's spatial ecology, as well as aid in developing bioenergetics models, which effectively describe the growth, reproduction, mortality, and overall foraging behaviours of fish.

Within the near future, climate change is expected to result in global increases in water temperatures, and fluctuations in water clarity, ice cover, $\mathrm{pH}$, and water levels (Magnuson et al. 1997; Schindler 2001). As a result, Magnuson et al. (1997) report climate change to have a considerable range of biological effects including increases in the thermal habitat (i.e. habitats that are capable of thermally support aquatic species) within deep stratified lakes, decreases in the thermal habitat for shallower lakes, increases in production for organisms that remain in habitats that are below their thermal optimas, an increase in the geographical range boundary for fish by as much as $600 \mathrm{~km}$, and an 
increase in invasion events of warm water species. As the Laurentian Great Lakes are considered vulnerable to climate change (Magnuson et al. 1997), information on how key fish species may respond to the changes in water temperatures is of critical importance.

Although a vast literature exists on the importance of temperature in the lifespan of aquatic organisms, the majority of that information stems from laboratory studies (Beitinger 2000). Consequently, there exists a gap in the literature on the thermal biology of fish in the wild. Historically, researchers have relied on laboratory means to measure preferred temperatures of fish species. Recent advances in technology have since led to the development of a number of tools (e.g. acoustic telemetry tags with capabilities of transmitting depth and temperature data, and internal biologgers), which allow researchers to accurately study the thermal biology of fish in the wild.

For the purposes of this study, I focus on describing the thermal ecology of three key fish species in the Laurentian Great Lakes. The Laurentian Great Lakes - which consist of Lake Superior, Lake Huron, Lake Michigan, Lake Erie, and Lake Ontario - are the largest group of freshwater lakes containing over $20 \%$ of the world's total freshwater, and covering a surface area of $244000 \mathrm{~km}^{2}$ (Magnuson et al. 1997). The Laurentian Great Lakes are considered both socially and economically important supporting approximately 34 million people in both Canada and the United States (GLIN 2010), and generating a billion dollar commercial and recreational fishery (Great Lakes Waterways Management Forum 2001).

The goal of my thesis is to generate information on the thermal ecology of three popular game fish species in the Laurentian Great Lakes: walleye (Sander vitreus), northern pike 
(Esox lucius) and largemouth bass (Micropterus salmoides). The objective of my first chapter is to analyze the thermal biology of walleye in Lake Erie and Lake Huron by examining differences in the thermal habitat selection between the two lakes, as well as looking at any differences in thermal experiences in Lake Huron between fish that migrate to different parts within the lake over the course of a year. To do so, thermal loggers (iButtons) paired with acoustic transmitters were implanted into walleye in 2011 and harvested within the following years. The goal of my second chapter is to compare the thermal ecology and depth preferences of largemouth bass and northern pike in a nearshore environment of Lake Ontario, specifically the Toronto Harbour. Collectively this work will generate essential knowledge on the thermal ecology of these freshwater fish species and operate as a tool for managers in developing bioenergetic models, which may help predict any consequences of the impending increases in nearshore water temperatures 


\section{Chapter 2 - The thermal biology of adult walleye (Sander vitreus) in Lakes Erie and Huron.}

\subsection{Abstract}

The purpose of this study was to characterize thermal patterns of adult walleye from lakes Erie and Huron using internally implanted biologgers to assess the effects of sex, fish size, diel periods, and lake using generalized additive mixed models. Sex, size, and diel periods had no effect on thermal occupancy of adult walleye in either lake. Thermal occupancy differed between lakes and seasons. Walleye from Lake Erie generally experienced higher temperatures throughout the spring and summer months than did walleye in Lake Huron, likely due to limnological differences between the lakes. Tagged walleye that remained in Saginaw Bay, Lake Huron (i.e., adjacent to the release location), experienced higher temperatures, and thus accumulated more thermal units (the amount of temperature units amassed over time) throughout the year as opposed to those migrating to the main basin of Lake Huron. Walleye that migrated toward the southern end of Lake Huron occupied higher temperatures than those that moved toward the north. Consequently, walleye that emigrated from Saginaw Bay experienced thermal environments that were more favourable for growth as they spent more time within their thermal optimas than those that remained in Saginaw Bay. Results presented in this manuscript provide information on the thermal experience of wild fish in a large lake, and could be used to refine sex- and lake-specific bioenergetics models of walleye in the Great Lakes to enable the testing of ecological hypotheses. 


\subsection{Introduction}

Walleye Sander vitreus provides an economically valuable resource in the Laurentian Great Lakes of North America to recreational and commercial fisheries that generate tens of millions of dollars annually (Fielder et al., 2014; Melstrom and Lupi, 2013; Roseman et al., 2008). Commercial fisheries in Lake Huron date back to the 1880s and once supported the second largest walleye fishery in North America, producing an average of 458 metric tonnes of fish annually (Brown et al., 1999; Baldwin and Salfeld, 1962). However, walleye populations declined during the 1950s due to overfishing and a series of poor year classes, presumably due to diminished water quality and degraded spawning habitat (Schneider and Leach, 1977), and fry predation by the invasive alewife Alosa pseudoharengus (Madenjian et al., 2008). Reestablishment of walleye populations occurred during the $1980 \mathrm{~s}$ as a direct result of improvements in water quality and fingerling stocking (Schneider and Leach, 1977; Fielder and Baker, 2004) and due to a collapse of alewife populations in the 2000s (Madenjian et al., 2008) leading to a full recovery in 2009 of the Saginaw Bay stock of walleyes (the single largest source within Lake Huron; Fielder and Thomas, 2014).

Lake Erie has the largest walleye fishery of all five Laurentian Great Lakes (Roseman et al., 2008; Fielder, 2002). Historically, commercial records indicate that the harvest of walleye stocks in Lake Erie date back to 1867 (Baldwin et al., 2002) with yields increasing until the mid-1950s reaching a peak of approximately 7000 tonnes (Nepszy, 1977; Schneider and Leach, 1977). A collapse of Walleye populations in Lake Erie reached severe levels by 1960 as a direct result of the overexploitation of walleye stocks, combined with the effects of pollution, eutrophication, and severe spawning 
habitat modifications (Koonce et al., 1996). The enactment of fishing quotas coupled with habitat remediation efforts (Hatch et al., 1987; Ryan et al., 2003) have since allowed walleye populations to recover in Lake Erie.

As poikilotherms, temperature has been labeled the "master" abiotic factor (Brett, 1971), and variations in ambient water temperatures can affect physiological (e.g., growth, swimming speed, and digestion), biochemical (e.g., enzymatic activities), and life-history activities (e.g., maturation, reproduction, and migrations) (Fry, 1971). For many fish species (see Pierce et al., 2013; Tirsgaard et al., 2015), laboratory studies have shown that thermal optima change throughout ontogeny. With walleye, thermal optima for early life stages $\left(22{ }^{\circ} \mathrm{C}\right.$; Koenst and Smith 1976; Huh et al., 1976; Kelso, 1972) have been determined to be slightly higher than optimas for mature fish $\left(18-22{ }^{\circ} \mathrm{C}\right.$; Christie and Reiger, 1988). Although a general understanding exists for many species of fish of the potential effects of temperature, little is known on the available thermal habitat of Lake Erie and Lake Huron, and thus further knowledge regarding the thermal regimes experienced by Great Lakes walleye is required to aid in better understanding growth rates, maturation schedules, foraging behaviour, and year-class strength of wild walleye in relation to changes in environmental temperatures.

I focused on the thermal biology of two adult walleye populations in two physically and limnologically distinct lakes. Specifically, I investigated walleye in Lake Huron that used the Tittabawassee River for spawning, and walleye from Lake Erie that spawned in the Maumee River. My objectives were to (1) describe and compare seasonal patterns of temperature occupancy by adult walleye and assess the effects of sex, size, diel periods, and location on those patterns, (2) model the annual thermal experience of 
Lake Erie and Lake Huron walleye, and (3) determine whether differences exist in the thermal experience of Lake Huron walleye by comparing accumulated thermal units among walleye from the subpopulation resident in Saginaw Bay (adjacent to the release site) vs. walleye using northern Lake Huron during summer and fall, vs. walleye using southern Lake Huron during summer and fall. Results presented in this manuscript provide information on the thermal experience of wild fish in a large lake, and could be used to refine sex- and lake-specific bioenergetics models of walleye in the Great Lakes to improve management (Hansen et al., 1993) and enable the testing of ecological hypotheses (e.g. estimating the consumption and growth of walleye in the Great Lakes, allowing for the regulation of stocking and harvest of the species; evaluating recruitment dynamics of walleye; and tracking contaminant accumulation in walleye populations based off prey populations).

\subsection{Methods}

\subsubsection{Study Site and Fish Collection}

Adult walleye were captured at two sites using boat-mounted electrofishing gear, during the spring spawning (between March and April 2011) run: 1) below Dow Dam on the Tittabawassee River $\left(4^{\circ} 36^{\prime} 24.2^{\prime \prime} \mathrm{N} 84^{\circ} 14^{\prime} 23.1^{\prime \prime}\right)$ of Lake Huron, and 2) Orleans Park along the Maumee River $\left(41^{\circ} 33^{\prime} 37.2^{\prime \prime N} 83^{\circ} 38^{\prime} 38.1^{\prime \prime W}\right)$ of Lake Erie (Fig. 1). Fish selected for tagging were limited to those at or above the legal recreational angling length limit in Michigan and Ohio $(>381 \mathrm{~mm})$ and were transferred to $380 \mathrm{~L}$ holding tanks after total length, weight, and sex were recorded for each individual. Dorsal spines were taken to non-lethally (see Brusher and Schull, 2009) estimate the age of individual walleye, a procedure that is routinely used by management agencies in the Great Lakes Basin 
(Erickson, 1983). In total, 199 individuals from Lake Huron (101 females and 98 males), and 200 (97 females and 103 males) individuals from Lake Erie, were implanted with acoustic transmitters (V16-4x; $16 \mathrm{~mm}$ dia. x $86 \mathrm{~mm}, 24 \mathrm{~g}$; battery life $=1338 \mathrm{~d}$, Vemco, Halifax, Nova Scotia). The acoustic transmitters were set to emit a tag-specific code $(69 \mathrm{kHz})$ at intervals between 60 and 180 seconds (mean: 120 seconds) and were coupled with an iButton thermal logger $\left(\mathrm{DS} 1921 \mathrm{z}\right.$; resolution $= \pm 0.1^{\circ} \mathrm{C}$; accuracy $=0.4 \pm 0.3{ }^{\circ} \mathrm{C}$, precision $=0.2 \pm 0.3{ }^{\circ} \mathrm{C}$, Maxim Integrated Products, Inc., Sunnyvale, California) (Donaldson et al., 2009) using a hot glue gun and the affixed logger was dipped in a waterproof coating (Plasti Dip, Performix Brand, Blaine, MN). iButtons were programmed to record temperatures at four-hour intervals for a period of approximately one year.

\subsubsection{Acoustic tag and thermistor implanting}

Prior to surgery, a walleye was transferred from a holding tank and anesthetized using a portable electroanesthesia system (PES; Smith-Root, Vancouver, Washington) operating at $35 \mathrm{~V}$ pulsed direct current. Electroanesthesia using pulsed direct current results in immediate induction, quick recovery, and high survival of walleye (Vandergoot et al., 2011). Treatments of three seconds induced stage-4 anesthesia for several minutes, allowing sufficient time for surgical implantation of the acoustic transmitters-iButtons. All surgical procedures followed guidelines outlined by Cooke et al. (2011). While sedated, fish were placed on a v-shaped surgical table, lined with soft, non-slip material. A constant flow of fresh water was pumped using a recirculation pump across each individual's gills to provide oxygen. All surgical tools were cleaned with povidone iodine and rinsed with deionized water before surgery; transmitters were similarly disinfected 
prior to being implanted. A small incision was made along the ventral side of each fish, posterior to the pelvic girdle. Each acoustic tag with iButton was placed into the coelom and the incision was closed with two to three absorbable monofilament sutures (PDS-II, 3-0, Ethicon, Somerville, NJ). A single experienced surgeon implanted all transmitters to reduce variation in fish survival and recovery; average surgery time was 142 seconds. Each fish was also tagged with two external anchor tags (Floy Manufacturing, Seattle, Washington) inserted between the dorsal pterygiophores to allow for identification of fish implanted with transmitters and promoted return of tags from walleye caught in the fishery. After surgery, fish were returned into holding tanks to recover. After the recovery period (30 min), individuals were released near the location where captured.

\subsubsection{Study Design}

During summer 2010, 140 stationary receivers (VR2W, 69 kHz, Vemco; Fig. 1) were installed in Lake Huron where they remained throughout the study period, except for periods of maintenance and data downloads (See Hayden et al., 2014). Receivers were placed in several perpendicular lines out from the shoreline, across bay mouths, and in rivers to monitor walleye movement (Fig. 1). Double receiver lines were deployed across Saginaw Bay to gather information regarding walleye movement in and out of Saginaw Bay. Receiver lines positioned perpendicular to the shoreline were restricted to depths $<40 \mathrm{~m}$, extending 3 to $10 \mathrm{~km}$ offshore. In shallower depths (less than $2 \mathrm{~m}$ ), deployed receivers were attached to existing structure or steel anchor posts buried in the substrate. Receivers deployed in deep waters $(>2 \mathrm{~m})$, were attached to a concrete anchor connected to a buoy. Receivers were placed on stainless steel cable, suspended at depths of 1-3 m above the lake bottom. Refer to Hayden et al. (2014) for complete information 
on static range testing, and receiver line detection probabilities. Thermal data were obtained via returned transmitter/iButton units from tagged fish caught in the fisheries. A monetary reward of \$100 USD was offered to anyone that harvested tagged walleye and returned the acoustic tag and iButton to the investigators.

\subsubsection{Data Analysis}

To test for seasonal differences in thermal experiences of walleye in lakes Erie and Huron walleye, two-sample t-tests were performed on minimum, maximum, and average temperatures for each fish each season in order to estimate the differences in the thermal extremes walleye may experience in either lake. F-tests were done on average temperatures for each season to determine any variability between lakes. Maximum and minimum values for each lake were determined by averaging the highest and lowest of temperatures experienced by individual walleye during each season. Spring corresponded to dates between March 20 $0^{\text {th }}, 2011$ and June $20^{\text {th }}, 2011$; summer corresponded to dates between June $21^{\text {st }}, 2011$ and September $21^{\text {st }}$, 2011; fall corresponded to dates between September 22 2011 and December 20 2 th, 2011 ; and winter corresponded to dates between December $21^{\text {st }}, 2011$, and March $19^{\text {th }}, 2012$. As a result of variations in the timing of fish being caught (i.e., the majority of walleye being caught earlier in the year), estimates of thermal experiences were restricted to date from fewer individuals during later parts of the year (see Fig. 2 for exact numbers).

Based on seasonal temperature variations experienced by walleye over time for lakes Erie and Huron, non-linear relationships existed between temperature experienced and time. Because time (i.e. month sequence) was a covariate of interest, time was analyzed for its effect on the response variable (temperature) using a generalized additive 
mixed model (GAMM) that included individual fish ID as a random effect (random intercept model). In addition, a correlation structure and variance structure were included to account for autocorrelation in the residuals and heterogeneity across months, respectively (Zuur et al., 2009). To determine the final model, the significance of variables (i.e., sex, size, diel periods, locations, and any interactions that may be occurring) was assessed using backwards model selection from a global model (i.e., model containing all variables of interest). Using this approach, we initially fitted our model using all of our variables of interest and continued on by sequentially dropping the least significant variable, as long as it was not significant at our chosen value of $\alpha=$ 0.025. For this analysis, we used a more conservative $p$-value to assess the importance of each variable (Wood, 2006). Model residuals were plotted and examined to determine whether model assumptions were not violated (Zuur et al., 2009).

To detect differences in the thermal experiences of walleye that migrate out of Saginaw Bay into Lake Huron versus walleye that remain in Saginaw Bay, a Tukey's range test was used in conjunction with a one-way analysis of variance (ANOVA) using temperature data from Lake Huron walleye. For this analysis, accumulated thermal units (ATU; the amount of temperature units amassed over time) were used in order to provide an estimate of the affect emigrating out of Saginaw Bay has on the thermal experience of Lake Huron walleye. The dependent variable in the ANOVA was accumulated thermal units for each fish and the main effect was subpopulation (three levels: Saginaw Bay subpopulation, northward-migrating subpopulation, southward-migrating subpopulation). We calculated ATUs by first averaging recorded temperatures for each day, and then summing average daily temperature from 5 April 2011 through 11 October 2011. We 
used $0{ }^{\circ} \mathrm{C}$ as a baseline for ATU calculations. The final day for ATU calculations was 11 October 2011 to optimize sample size for each of the three groups. Statistical significance was set at $\mathrm{P}<0.05$. This part of the analysis was limited to specifically Lake Huron walleye, as previous studies have already examined the potential benefits (e.g. higher growth rates) of migrating walleye in Lake Erie (see Wang et al., 2007; Kershner et al., 1999). All analyses used the $\mathrm{R}$ statistical programming environment ( $\mathrm{R}$ Development Core Team, 2012). Analyses completed by Hayden et al. (2014) on walleye movement in Lake Huron were used to classify each of the tagged Lake Huron walleye into one of the three subpopulations.

\subsection{Results}

2.4.1 Thermal variability between Lake Erie and Lake Huron walleye Thermal data was downloaded from 70 tagged individuals (18\% of total tagged) caught in the fishery (see Table 1 for summary information). Walleye experienced different temperatures in Lake Erie vs. Lake Huron during specific periods of the year as judged by mean maximum water temperature recorded. Lake Erie walleye used warmer maximum temperature water during the summer $\left(25.0{ }^{\circ} \mathrm{C}\right)$ and fall $\left(18.3{ }^{\circ} \mathrm{C}\right)$ than Lake Huron fish $\left(23.6{ }^{\circ} \mathrm{C}, 16.5{ }^{\circ} \mathrm{C}\right.$ respectively, $\mathrm{P}<0.05$, Fig 2.a). During the summer, Lake Erie walleye resided in mean warmer temperature water than Lake Huron fish (mean $21.14{ }^{\circ} \mathrm{C}$ vs. $19.30{ }^{\circ} \mathrm{C}, \mathrm{P}=0.004$, Fig $2 \mathrm{~b}$ ). Mean temperatures experienced of Lake Erie walleye were less variable throughout the fall $(\mathrm{F}=0.049, \mathrm{P}<0.01)$ and winter $(\mathrm{F}=$ 0.006, $\mathrm{P}<0.001)$ seasons, when compared to individuals from Lake Huron. Similarly, the mean minimum water temperature recorded for Lake Erie walleye in spring and summer was higher than for Lake Huron walleye (Fig. 2.c). A few individuals from Lake 
Huron were recorded occupying temperatures warmer than $15{ }^{\circ} \mathrm{C}$ during parts of the winter season.

\subsubsection{Effects of sex, size, and diel periods}

Overall, walleye thermal regimes closely mirrored normal temporal temperature patterns with water temperatures warming throughout the spring season, reaching a maximum in late summer and declining through the fall and into the winter (Fig. 3). No differences in thermal experiences between the sexes of mature walleye were found within either lake $(\mathrm{P}>0.025)$. Likewise, the thermal experience of walleye was not related to their total length or diel period $(\mathrm{P}>0.025)$. In contrast, season and location (i.e. Lake Huron and Lake Erie) explained temperatures experienced by walleye ( $\mathrm{P}<$ 0.025 ), and accounted for $92 \%$ of the variation in the data (Table $2 ; \mathrm{R}^{2}=0.92$ ). Based on the model, the expected thermal experiences of walleye were plotted throughout the year; yielding an estimate of the range of temperatures walleye can be found at any given time for both lakes in 2012 (see Fig. 4, dashed lines represent the 95\% confidence intervals). 2.4.3 Thermal variability between different groups of migrating walleye in Lake Huron

Of the 45 individuals evaluated from Lake Huron, $64 \%(\mathrm{n}=29)$ remained within Saginaw Bay after spawning, whereas $18 \%(\mathrm{n}=8)$ migrated to the northern portion of Lake Huron and $18 \%(\mathrm{n}=8)$ migrated to the southern portion of Lake Huron. Of the individuals that remained in Saginaw Bay, 59\% were female, with an average age of 7.2 years $(\mathrm{SD}=2.27)$ and an average length of $550 \mathrm{~mm}(\mathrm{SD}=70.2)$. Of the individuals that migrated to northern parts of Lake Huron, $63 \%$ were female, with an average age of 9.4 years $(\mathrm{SD}=2.32)$ and an average length of $590 \mathrm{~mm}(\mathrm{SD}=71.4)$. Similarly, of the individuals that migrated to southern parts of Lake Huron, $75 \%$ were female with an 
average age of 6.8 years $(\mathrm{SD}=0.834)$ and an average length of $560 \mathrm{~mm}(\mathrm{SD}=51.5)$. Results of the one-way ANOVA revealed differences in thermal experiences among the three walleye subpopulations $(\mathrm{F}(2,17)=32.319, \mathrm{P}<0.001$, Fig. 5). Individuals remaining in Saginaw Bay accumulated 648 more ATUs than individuals migrating to the north ( $\mathrm{P}<0.0001$, Table 3$)$, and 461 more ATUs than to the south $(\mathrm{P}<0.0001$, Table $3)$.

\subsection{Discussion}

2.5.1 Inter and intra-lake thermal variability of Great Lakes walleye

Differences in the thermal experiences of walleye are partly attributable to differences in the physical features between the two lakes. Lake Erie, being further south and the smaller and shallower of the two lakes (Fuller et al., 1995), warms more quickly in the spring and summer months, and on average retains mean surface water temperatures more than $5{ }^{\circ} \mathrm{C}$ higher than Lake Huron during mid-summer (Dobiesz and Lester, 2009). It is however impossible to fully justify the observed thermal differences to simply variations in lake type as we lack the replication needed to control for other variables associated with deep and shallow lakes. Temperature plays a key role in the growth and maturation of walleye, with optimal temperatures ranging between 18 and 22 ${ }^{\circ} \mathrm{C}$ (Christie and Reiger, 1988). Individuals occupying habitats within this range undergo the highest levels of growth, as well as generate strong subsequent year classes, as individuals can allocate more energy to gamete production (Kitchell et al., 1977). However, increases in temperatures above these limits can lead to adverse effects on the physiology of fish. Temperatures exceeding optimal levels are correlated with decreased growth rates (Kershner et al., 1999), higher metabolic costs (Clarke and Johnston, 1999), 
and increased natural mortality rates (Houde, 1989). As such, fish residing in the warm waters of Lake Erie may experience a higher rate of early season growth, followed by a period of decreased growth rates during periods in the summer, when compared to individuals from Lake Huron, as temperatures in excess of $25{ }^{\circ} \mathrm{C}$ have been recorded. However, Lake Erie walleye may compensate for this by migrating toward the central and eastern basins where cool water habitat exists (Ryan et al., 2003; Wang et al., 2007).

Abnormally high temperatures experienced by some Lake Huron walleye in the winter were likely the result of fish occupying thermal effluents associated with manufacturing establishments along the shore of Lake Huron. Telemetry data revealed these individuals overwintered in Saginaw Bay, and Lake St. Clair (Hayden et al., 2014). Historically, increases in water temperatures up to $10{ }^{\circ} \mathrm{C}$ have been observed in the Tittabawassee River as a result of water being used for cooling purposes (Gannon, 1963). Hence, a few individuals may have selected specific locations of Lake Huron that are exposed to thermal effluents, explaining the increased temperatures we observed. Previous telemetry studies on yellow perch, a similar cool-water fish, have shown high numbers of individuals actively selecting areas in a thermal discharge bay for much of the winter (Ross and Sniff, 1982). Consequently, walleye inhabiting thermal plumes throughout winter months may show an analogous preference for areas of increased water temperatures and, in turn, benefit from a lengthened growing season that extends into the winter months.

\subsubsection{Intra-lake thermal variability of Great Lakes walleye}

Individuals that remained in Saginaw Bay were able to accumulate more thermal units as they occupied higher water temperatures when compared to fish that migrated 
out of Saginaw Bay and into the main basin of Lake Huron. As such, walleye that remain in Saginaw Bay have the potential to be at a disadvantage during the summer, as temperatures exceeded thermal optima, and could result in depressed growth. Although individuals that remained in Saginaw Bay did not migrate into other parts of Lake Huron, due to the incomplete coverage of our receiver lines in the lake, we could not determine whether northern or southern moving fish reversed and took paths outside of our detection ranges along the shores of Lake Huron. As such, walleye could possibly be detected on northern receivers but then turn south without being detected.

In Lake Erie, walleye during the summer move to the central and eastern basins that have cooler water than the eastern basin (Wang et al., 2007). Western basin walleye that showed eastward migrations were larger and older than those individuals that did not migrate from the western basin. A bioenergetic analysis by Kershner et al. (1999) revealed two growth peaks associated with eastward migratory walleye, and only a single growth peak for individuals that remained in the western basin. As the western basin warmed at a greater rate than the other basins, optimal growth periods occurred earlier in the season and these periods would eventually shift eastward to the central basin in the early summer. Consequently, migratory fish exploited growth peaks in both basins and experienced optimal temperatures for a longer period of time. Thus, migratory individuals achieved a thermal advantage and experienced higher growth rates than their non-migratory counterparts (Kershner et al., 1999). Walleye that emigrated from Saginaw Bay were likely demonstrating analogous behavior to walleye from Lake Erie and thus behaviourally thermoregulating to access optimal growth periods and temperatures associated with Saginaw Bay and northern and southern basins of Lake Huron. 
Migratory walleye in both lakes may also have benefited through behavioural thermoregulation by avoiding the damaging effects on fish that become evident as temperatures approach upper critical thresholds. High summer temperatures are known to cause significant losses in optimal thermal habitat for cool and cold-water species (Eaton and Scheller, 1996), and result in weight loss and stunted growth (Kitchell et al., 1977), an increase in the occurrences of bacterial and viral diseases (Snieszko, 1974), and ultimately increase in mortality rates when temperatures exceed maximum tolerable levels.

Migration from Saginaw Bay could also be the result of the quest for greater availability of forage fish. In Lake Ontario, specifically the Bay of Quinte, Bowlby and Hoyle (2011) show that many mature walleye migrated out of the bay into the deeper and cooler waters of Lake Ontario throughout the summer and early fall months to forage on alewife. The authors noted that the concentrated amounts of alewife might offset any disadvantages associated with lower temperatures than available in the Bay of Quinte. Similarly, movement of Lake Erie walleye has also been linked to spatial patterns of prey abundance, specifically soft-rayed fish (i.e., rainbow smelt Osmerus mordax, emerald Notropis atherinoides and spottail shiners Notropis hudsonius) that reside in the central and eastern basins in the summer (Wang et al., 2007).

A more extensive study by Hayden et al. (2014), reported $57 \%$ of individuals remained in Saginaw Bay throughout the year and 43\% emigrated to either northern or southern parts of Lake Huron. Discrepancy in our results is likely caused by us only using the biologger data from individuals caught earlier than when the majority of walleye left the bay, whereas the outmigration rates presented by Hayden et al. (2014) 
included individuals at liberty as well as those harvested. It is also important to note that this study is limited to one year of temperature data due to the characteristics of the biologgers. Interpretation of our statistical results should thus be taken carefully as the benefits and/or disadvantages of remaining in Saginaw Bay are likely to change with the annual variation in water temperatures of Lake Huron. For example, during a cooler than normal year individuals that remain in Saginaw Bay may be at an advantage, as temperatures would be unlikely to exceed thermal limits, compared to individuals that migrate out of the bay.

\subsubsection{Variables Influencing Thermal Habitat Experience}

Despite the growing body of evidence regarding the effects of interspecific variables (e.g. sex, size) on the thermal biology of ectothermic organisms (Sagonas et al., 2013; Tang et al., 2013; Huey and Pianka, 2007), few studies have focused on fish. In addition to field experiments, Pearson et al. (2003) stated that research on the thermal biology of an organism should also include a laboratory component so that thermal preferences observed in the wild can be compared to those observed under controlled conditions. We did not incorporate a laboratory component in our study given the extensive body of work already published on walleye. Previous studies with adult walleye have suggested thermal optima for growth ranging between 18 and $22{ }^{\circ} \mathrm{C}$ (Christie and Regier, 1988). However, individuals that we observed spent a relatively small proportion of their time within this optimal temperature range due to the seasonal variation in water temperatures during an entire year and so we examined various other biological variables that may have contributed to the annual thermal regimes of walleye in lakes Huron and Lake Erie. 
Adult walleye are negatively phototactic organisms (Bulkowski and Meade, 1983) and progressively move into deep/cool waters during their ontogeny. If walleye in either lake were forced into deep waters of the hypoliminion during daytime, we would anticipate diel movement to occur with regards to their thermal habitat. However, our results showed no differences between day and night temperatures $(\mathrm{P}>0.025)$. A possible explanation for the lack of any day/night fluctuations can be explained by periodic thermal mixing within both lakes. When testing the effects of each variable, we did so over the course of an entire year. Stratification properties of northern temperate lakes reveal isothermal profiles for the majority of the year (Bai et al., 2013). In central and eastern Lake Erie, stratification is first established in early July and continues until late September or early October; stratification typically does not occur in western Lake Erie (Schertzer et al., 1987). Full stratification of Lake Huron does not occur until mid July and lasts until waters become fully isothermal again by mid-October (Sheng and Rao, 2006). As these dates translate into roughly a third of the year, any effects that diel period may have on walleye thermal ecology may be masked by the isothermal conditions that occur during most of the year. Nonetheless, walleye temperatures were highly variable during parts of the summer months and random daily fluctuations, up to $8.9{ }^{\circ} \mathrm{C}$, were observed. Walleye in West Blue Lake, Manitoba, revealed similar patterns with regards to day and night thermal variation (Kelso, 1976). Adult walleye, between the ages of 2 and 5, used the epilimnion between 5 and 10 meters, and chose a fairly constant range of temperatures between 10.6 and $11.7{ }^{\circ} \mathrm{C}$, despite having temperatures from 5.1 to $14.7^{\circ} \mathrm{C}$ available. 
Our results revealed no differences in thermal experiences between the sexes of mature walleye in either lake. Likewise, thermal habitat experience of walleye was not related to their total length. Female walleye tend to be larger at a specific age than their male counterparts (Rennie et al., 2008). Similar work on differences in freshwater fish species revealed no differences in thermal selectivity and responses between sexes (Cherry et al., 1975). Only mature walleye were used in this study. If immature fish had been tagged, differences in thermal experience may have emerged between immature and mature individuals. Many species of fish show size-dependent thermal preferences (McCauley and Huggins, 1979) such that optimal temperatures required for growth decrease with increasing body sizes (Morita et al., 2010). For example, clear differences in ontogenetic thermal preferenda of yellow perch were documented with juveniles selecting temperatures within a range of $20-20.3{ }^{\circ} \mathrm{C}$ while adults selected a range between $17.6-20.1{ }^{\circ} \mathrm{C}$ (McCauley and Read, 1973). Similarly, juvenile walleye experienced optimal growth at water temperatures of $26{ }^{\circ} \mathrm{C}$ (Hokanson and Koenst, 1986), whereas mature walleye prefer temperatures between $18-22{ }^{\circ} \mathrm{C}$ (Christie and Regier, 1988). Consideration of ontogenetic differences of the thermal preferences of walleye is needed to fully understand growth performances and thermal experiences of walleye.

The annual thermal experience of adult walleye in lakes Erie and Huron reported here will provide an important management tool to refine bioenergetics models for walleye in both lakes (Hartman and Kitchell, 2008; Hanson et al., 1997). For example, fish bioenergetics modeling has been used in managing the Chinook salmon (Oncorhynchus tshawytscha) fishery in Lake Michigan (Tsehaye et al., 2014; Madenjian, 
2011; Hansen et al., 1993) and the entire predator community of Lake Huron (He et al., 2014). Population models for salmonines have been coupled with fish bioenergetics models to generate estimates of annual consumption of prey fish. In turn, salmonine stocking rates have been adjusted based on model predictions. Petersen and Kitchell (2001) used bioenergetic modeling to predict changes in predation on juvenile salmon with climate change, and thus provided managers with a tool to predict future mortality on juvenile salmon and ultimately aid in recovery of the salmon stock.

In the near future, temperature is predicted to increase with climate change (Hayhoe et al., 2010; Magnuson et al., 1997), resulting in higher water temperatures. Magnuson et al. (1997) predicts climate change to cause a number of physical and biological changes including increases in thermocline depths, decreases of dissolved oxygen below thermocline, increases in phyto- and zooplankton, increases of warm-, cool-, and cold-water habitats in deep stratified lakes (opposite for shallow stratified lakes), and changes in the growth and production of fish species. Although some work has been done on predicting potential effects of climate change on different species on fish in Lakes Michigan and Erie (Magnuson et al., 1990), future studies should consider how climate change might affect available thermal habitat for native populations of fish (i.e. walleye) in all the Great Lakes.

Differences in thermal regimes experienced by walleye between lakes Erie and Huron were largely driven by differences in bathymetry between the two lakes, with Lake Erie being substantially shallower and warmer than Lake Huron. However, concluding that observed differences in the thermal experiences of walleye were caused solely by limnological differences would be an oversimplification. Walleye are likely 
faced with a decision to either stay in areas of the lake where temperatures exceed optimum levels and benefit from not having to expend energy, or alternatively to search for more thermally optimal areas and if found, benefit from reduced metabolic costs associated with colder temperatures. Thus, future research is needed to identify potential explanations as to why such differential behaviour exists within a population. 


\subsection{Acknowledgements}

Ohio Department of Natural Resources and Michigan Department of Natural Resources, and the US Geological Survey (Hammond Bay and Lake Erie Biological Stations) for their technical and logistical support in the collection of walleye. We also thank Sean Landsman, Sarah Seegert, and Scott Miehls in aiding with fish surgeries. Financial support was provided by the Great Lakes Fishery Commission from funds provided by Great Lakes Restoration Initiative appropriations (GL-00E23010-3), and by S. J. Cooke, who is supported by the Canada Research Chairs Program and the Natural Sciences and Engineering Research Council of Canada (NSERC). Use of trade, product, or firm names does not imply endorsement by the U. S. Government. This article is Contribution 1965

of the U. S. Geological Survey Great Lakes Science Center and Contribution 13 of the Great Lakes Acoustic Telemetry Observation System. 


\subsection{Tables}

Table 2.7.1: Summary of physical attributes (e.g., sex, number of individuals, length, and age) and days at liberty after tagging of adult walleye (Sander vitreus) caught by the Lake Erie and Lake Huron fisheries as of October of 2013. Days at liberty refer to the time individual walleye spent in each lake before being caught.

\begin{tabular}{rcccc}
\hline & \multicolumn{2}{c}{ Lake Huron } & \multicolumn{2}{c}{ Lake Erie } \\
\hline Sex & M & F & M & F \\
Total numbers & 17 & 28 & 14 & 11 \\
Mean Age (years) & 8 & 8 & 7 & 10 \\
Maximum & 13 & 14 & 12 & 13 \\
Minimum & 4 & 4 & 4 & 8 \\
Standard Deviation & 2.24 & 2.42 & 2.48 & 2.14 \\
Mean Length (mm) & 528 & 588 & 525 & 652 \\
Maximum & 712 & 781 & 602 & 781 \\
Minimum & 450 & 456 & 450 & 590 \\
Standard Deviation & 56.8 & 71.2 & 43.3 & 56.0 \\
Mean Days at Liberty & 167 & 187 & 85 & 207 \\
Maximum & 338 & 338 & 341 & 341 \\
Minimum & 33 & 22 & 3 & 63 \\
Standard Deviation & 115.4 & 129.3 & 112.6 & 122.9 \\
\hline
\end{tabular}


Table 2.7.2: The importance of fixed terms, variance covariate $(\beta)$, and correlation structure (Month|Fish ID) for our model predicting the thermal experience of walleye (Sander vitreus) in Lake Erie and Lake Huron. The approximate significance of the smoother (Month) for Lake Erie was $\left(\mathrm{F}_{8.231}=95.72, \mathrm{P}<0.0001\right)$ and for Lake Huron $\left(\mathrm{F}_{8.240}=209.0, \mathrm{P}<0.0001\right)$. Length, sex, size, diel period, were all insignificant in our model $(\mathrm{P}>0.025)$.

\begin{tabular}{lccc}
\hline Model Term & L Ratio & df & P-Value \\
\hline Location & 18.99 & 1 & $<0.001$ \\
Month $^{\beta}$ & 461.4 & 12 & $<0.001$ \\
(Month|Fish ID) & 1590 & 2 & $<0.001$ \\
\hline
\end{tabular}


Table 2.7.3: Results of one-way ANOVA and Tukey's range test applied to accumulated thermal units (ATUs) for walleye (Sander vitreus) from the following three Lake Huron subpopulations: (1) those fish migrating to northern Lake Huron, (2) those fish remaining in Saginaw Bay, and (3) those fish migrating to southern Lake Huron.

\begin{tabular}{|c|c|c|c|c|c|}
\hline Location & \multicolumn{3}{|c|}{ Accumulated Thermal Units } & T Value & Significance \\
\hline North & \multicolumn{3}{|c|}{2601} & 40.75 & \\
\hline Saginaw Bay & \multicolumn{3}{|c|}{3249} & 7.65 & $\mathrm{P}<0.0001$ \\
\hline South & \multicolumn{3}{|c|}{2789} & 2.08 & $\mathrm{P}=0.053$ \\
\hline Source & df & SS & MS & $\mathbf{F}$ & Significance \\
\hline Area & 2 & 1580257 & 790128 & 31.319 & $\mathrm{P}<0.0001$ \\
\hline Residuals & 17 & 415614 & 24448 & & \\
\hline
\end{tabular}




\subsection{Figures}

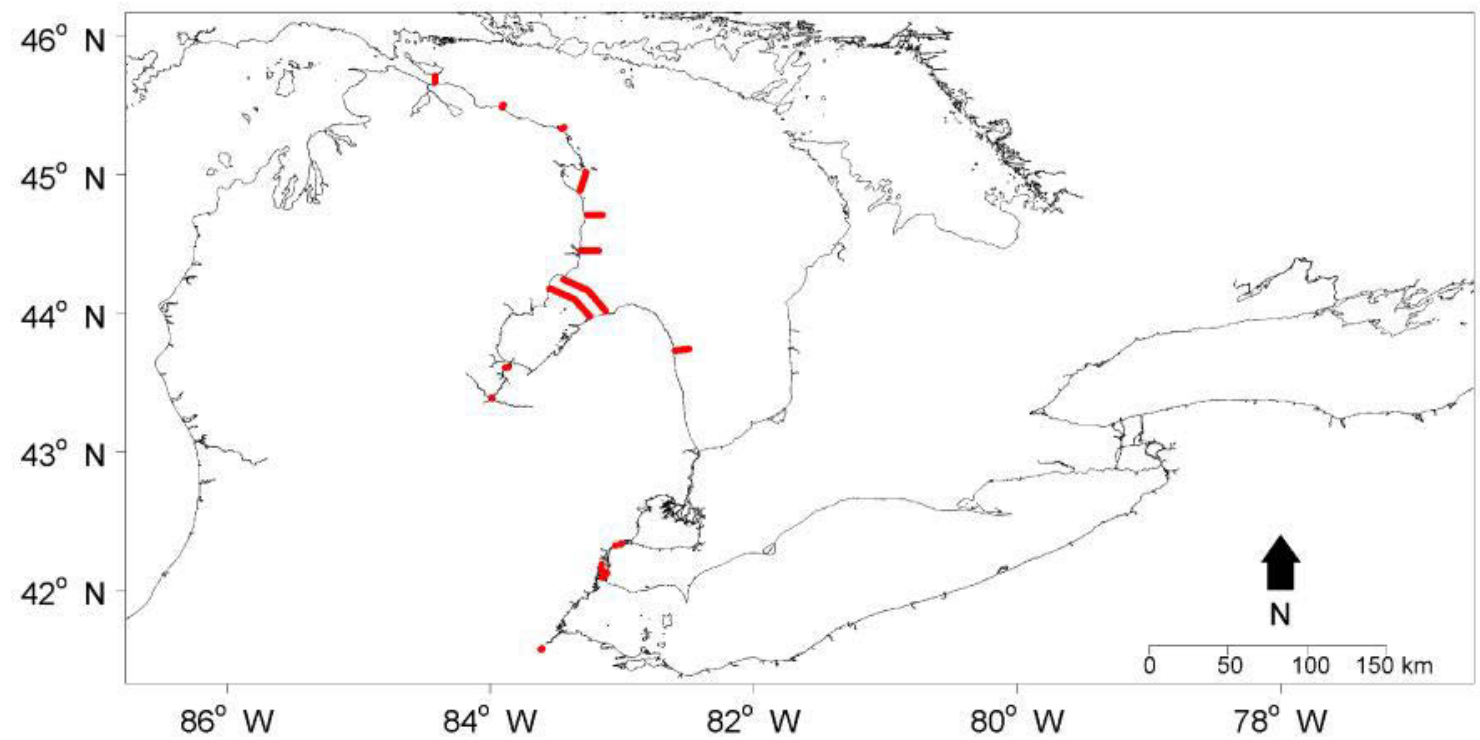

Figure 2.8.1. Collection sites for adult walleye (Sander vitreus) for Lake Erie (Orleans Park, Maumee River) and Lake Huron (Dow Dam, Tittabawassee River). Red dots represent the locations of individual VR2W acoustic telemetry receivers positioned in Lake Erie, Lake Huron, and along the Huron-Erie corridor, which includes the St. Clair River, Lake St. Clair, and the Detroit River. 


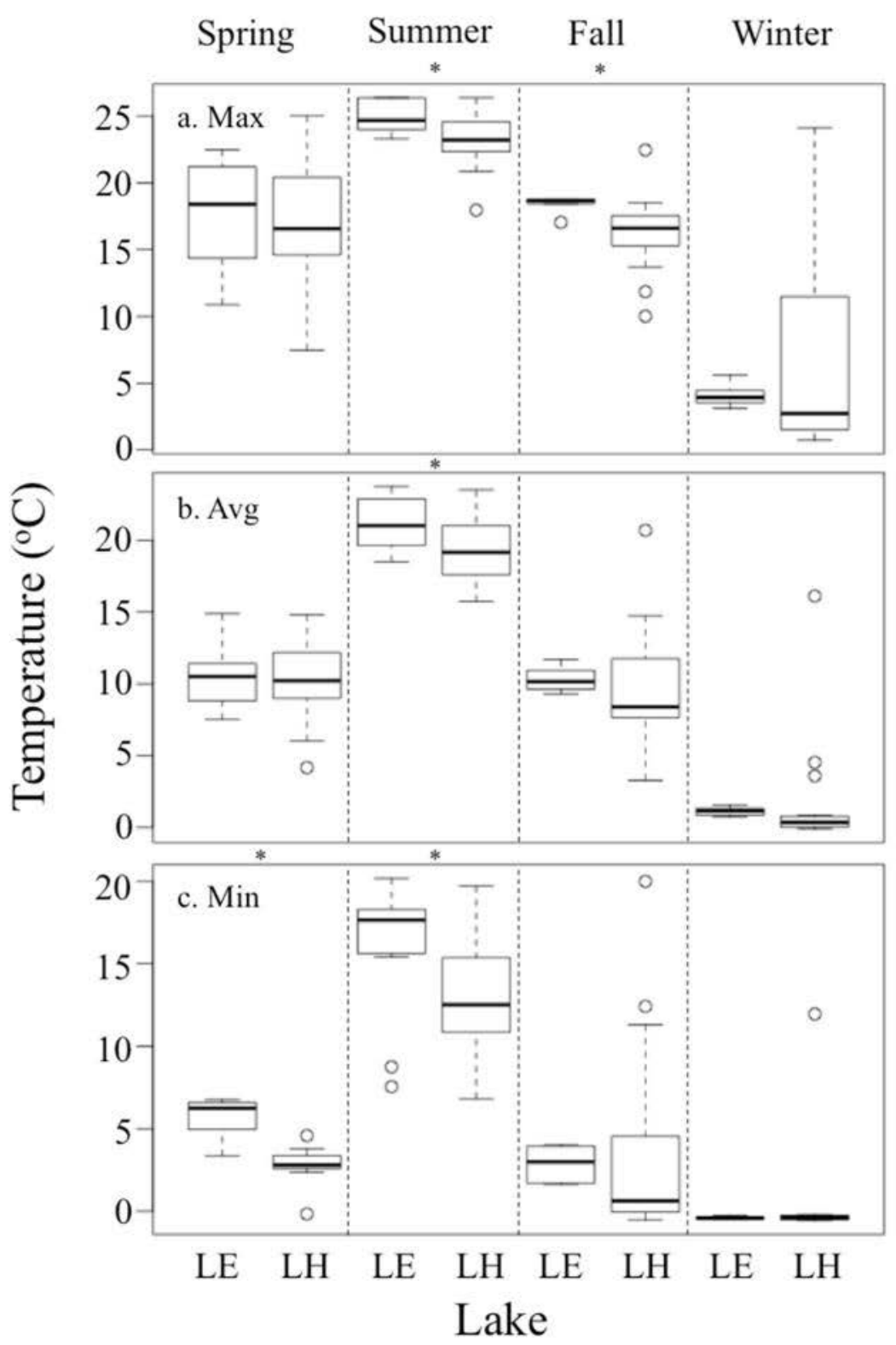

Figure 2.8.2. Thermal data for walleye (Sander vitreus) mean maximum seasonal temperatures (panel a), mean seasonal temperatures (panel b), and mean minimum seasonal temperatures (panel c) for both Lake Erie (labeled LE) and Lake Huron (labeled LH) individuals. Asterisks represent significant differences between lakes within seasons $(\mathrm{P}<0.05)$. The horizontal lines represent the means of each group. Whiskers represent the largest and smallest observations within each group that fall within $1.5 \mathrm{x}$ of the interquartile range. Observations that exceed this interquartile range are plotted as open circles. Mean maximum and minimum values for each lake were determined by averaging the highest and lowest of temperatures experienced by individual walleye during each season. 

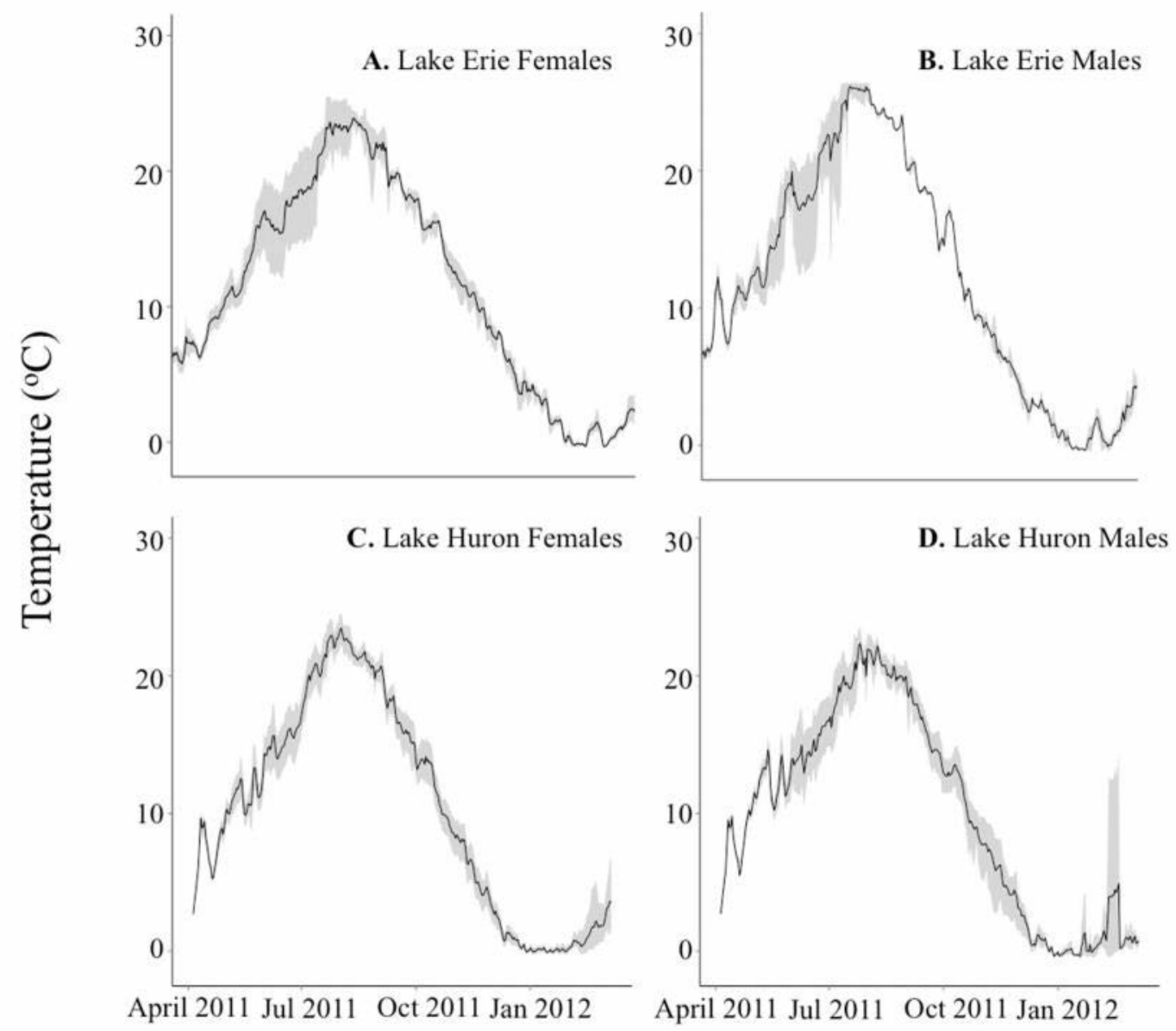

Date

Figure 2.8.3: Example thermal profiles typifying two female adult walleye (Sander vitreus) from Lake Erie and Lake Huron (panels A and C respectively), and two male adult walleye (Sander vitreus) from Lake Erie and Lake Huron (panels B and D respectively). Shaded areas represent the $95 \%$ confidence intervals. 


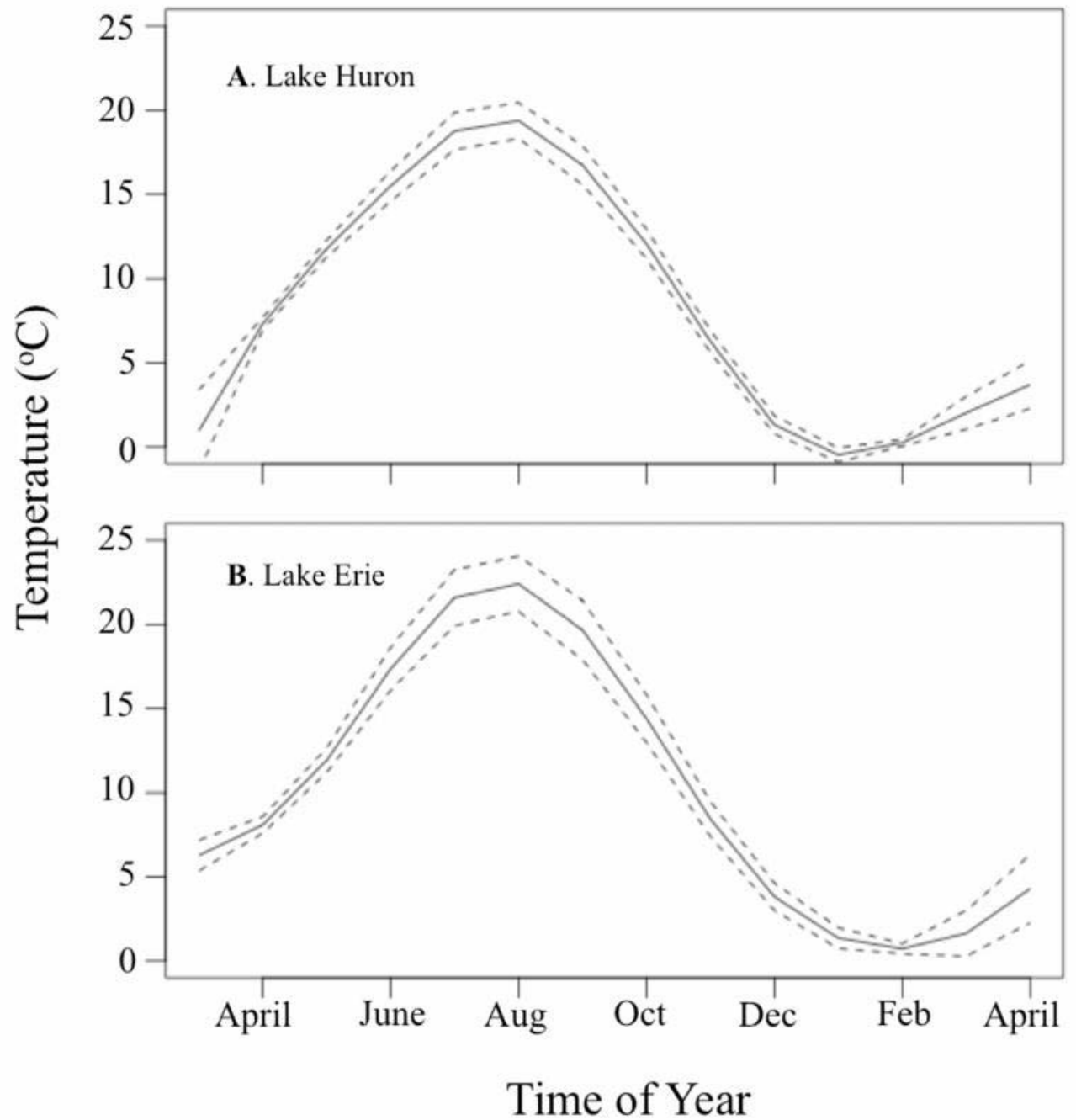

Figure 2.8.4: Predicted temperatures experienced by adult walleye (Sander vitreus) in Lake Huron (A) and Lake Erie (B) throughout the course of a year, with dashed lines representing the $95 \%$ confidence intervals. Values for predicted temperatures of each lake were obtained using a generalized additive mixed model. 


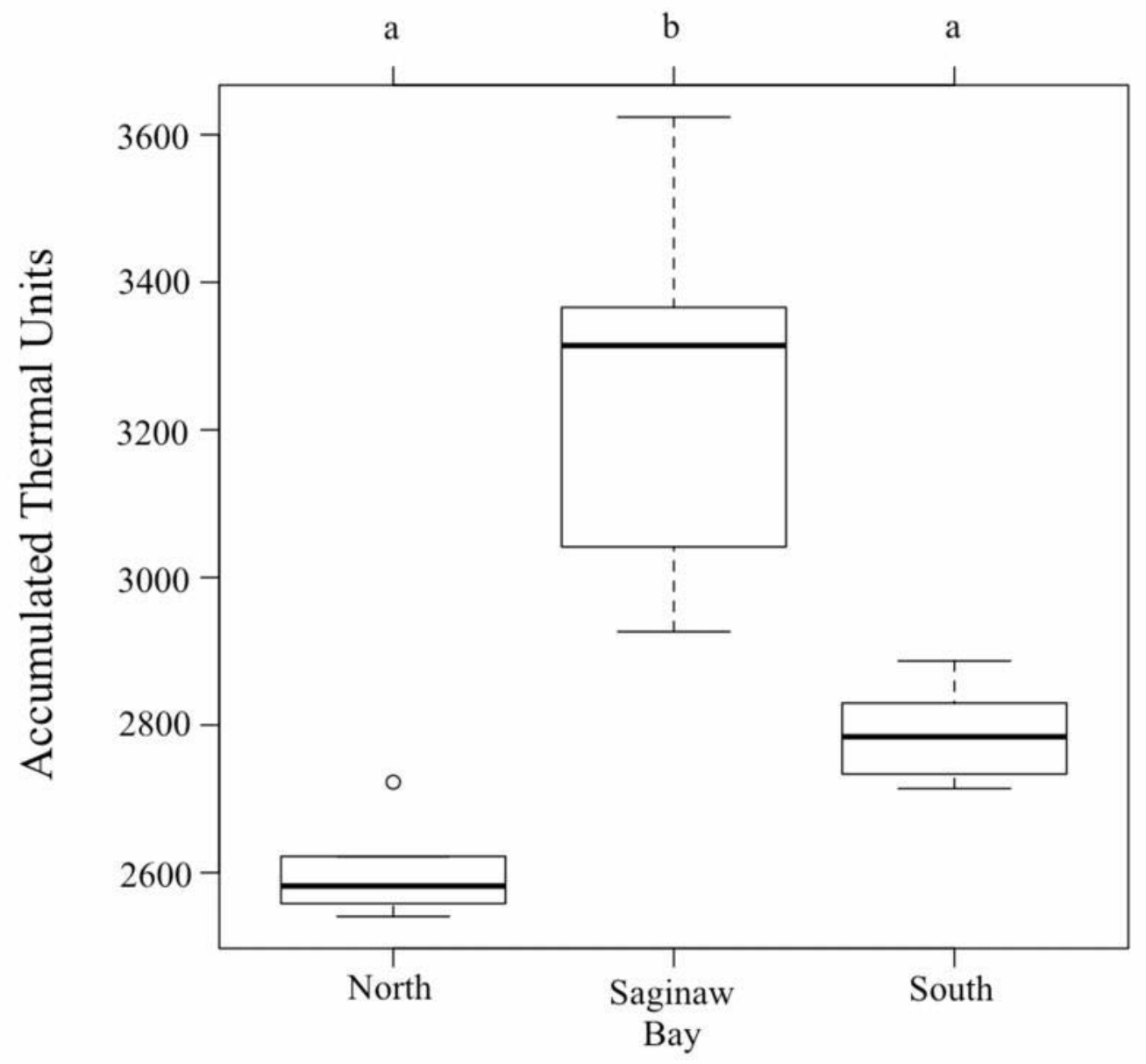

Migratory Direction

Figure 2.8.5: Box and whisker plot of the accumulated thermal units (ATUs) of walleye (Sander vitreus) who migrate north, remain in Saginaw Bay, or migrate south. The horizontal lines represent the means of each group. Whiskers represent the largest and smallest observations within each group that fall within $1.5 \mathrm{x}$ of the interquartile range. Observations that exceed this interquartile range are plotted as open circles. Different letters are representative of significant differences between groups. 


\section{Chapter 3 - Comparative thermal biology of northern pike (Esox lucius) and largemouth bass (Micropterus salmoides) in nearshore environments of Lake Ontario.}

\subsection{Abstract}

Biotelemetry tags that incorporate sensors, such as those that measure temperature and depth, have provided new opportunities for understanding the environmental relations and habitat requirements of wild fish. Here we monitored the depths and temperatures used by different sizes of northern pike (Esox lucius - total lengths [TL] 325-1003 mm) and largemouth bass (Micropterus salmoides - TL 271-535 mm) in the Toronto Harbour across an entire year using acoustic telemetry tags equipped with depth and temperature sensors and an expansive telemetry array. Largemouth bass and northern pike had similar thermal experiences throughout the majority of the year, with the exception of summer, where pike were observed in cooler waters than bass. Northern pike and largemouth bass used different depths throughout the year, with pike generally occupying deeper depths. Results indicated that depth was largely influenced by the main effects and all interactions between them (e.g. season, species, and body size), while thermal preferences were influenced by the main effects and an interaction between species and body size. As water temperatures exceeded $10{ }^{\circ} \mathrm{C}$, both northern pike and largemouth bass were observed to behaviourally thermoregulate and selected temperatures warmer than those in the vicinity of the telemetry stations at which they were detected. When water temperatures exceeded $20{ }^{\circ} \mathrm{C}$, northern pike were observed to select cooler waters. This study provides a thorough examinination of temperature and depth selection information of two important temperate fish species year round, including under ice. Such information will be useful for informing habitat management (e.g., identifying construction windows for in-water work) and modeling efforts. 


\subsection{Introduction}

Historically, the littoral regions of the Laurentian Great Lakes were composed of a vast array of wetlands, tributaries, marshes and bays (Francis et al. 1979). However, much of that landscape has since been changed, due to the development and urbanization of waterfront areas in Canada and the United States. The Toronto Harbour on the western end of Lake Ontario serves as a representative example. Urbanization of the Toronto Harbour dates back to the late 1700 s when government wharfs were constructed along the coastline to aid in handling the increasing numbers of cargo ships and by the mid 1800s, the Toronto Harbour shoreline was transformed entirely by government and commercial wharfs (Wickson 2002). Fueled by rapid economic development in the early 1900s, further urbanization of Toronto's waterfront occurred with the infilling of Ashbridge's Bay (Desfor and Vesalon 2008), an integral part of Toronto's aquatic ecology, resulting in the loss of aquatic habitat and ultimately a decrease in biodiversity. In recent decades, following the listing of Toronto Harbour as a Great Lakes Area of Concern (AOC; Hartig and Vallentyne 1989), great efforts have been expended in enhancing and restoring the structure and function of habitats and associated aquatic communities in Toronto Harbour AOC. Indeed, the same story of degradation (Regier and Kay 1996) and restoration (see Hartig and Vallentyne 1989; Mitsch and Wang 2000) through the development of so called "remedial action plans" (Hartig and Thomas 1988) has played out to some extent in all 43 AOCs in the Great Lakes. Although there are many delisting criteria used (George and Boyd 2007), one of the most common ones relates to the state of native fish communities including popular sportsfish that can be targeted by recreational anglers (Sproule-Jones 2002). 
Largemouth bass (Micropterus salmoides) and northern pike (Esox lucius) are two popular fish species present in many coastal areas of the Laurentian Great Lakes including Toronto Harbour (Bence and Smith 1999). Largemouth bass are a largely successful freshwater fish species, inhabiting the majority of aquatic habitats in North America (Brown et al. 2009). In Ontario, largemouth bass are known to prefer bodies of water greater than 0.1 ha, which consist of mainly a muddy or gravel substrate (Lasenby and Kerr 2000; Brown 2009). Typically, bass are found in depths of less than $6 \mathrm{~m}$ and favor lacustrine environments with shallow littoral zones, and widespread vegetation (Brown et al. 2009). Similarly, northern pike are a successful and broadly distributed fish species, occurring in the majority of lakes and rivers across North America, much of the United Kingdom (excluding Scotland; Lefevre 1999), and in Europe (Crossman 1996; Harvey 2009). There is much overlap in the preferred habitat of both species. Ideal pike habitat has been identified as vegetated areas of water that is less than $4 \mathrm{~m}$ in depth (Harvey 2009). Although much is known for both largemouth bass and northern pike, the majority of information concerning habitat usage has focused more on spatial ecology, and knowledge on the thermal and vertical (depth) components of habitat usage is lacking. Understanding those elements of fish biology is necessary to identify the detailed habitat requirements of species to inform habitat management activities such as enhancement projects to restore critical environments, and development of more robust habitat models.

As poikilotherms, temperature plays a vital role influencing many physiological processes, and growth for both largemouth bass and northern pike. Thus, temperature is traditionally regarded as the "master" abiotic factor (Brett 1971), and variations in 
ambient water temperatures can have an assortment of impacts on all biochemical (such as enzymatic activities), physiological (such as growth, swimming speed, and digestion), and life-history (such as maturation, reproduction, and migrations) processes (Fry 1971). Specific ranges of temperatures can regulate reproduction and growth in fish, which vary between species. Largemouth bass are classified as a warm-water fish species and thus have considerably higher thermal optima when compared to the northern pike. Optimal growth of mature largemouth bass has been known to occur at temperatures ranging from $24-30{ }^{\circ} \mathrm{C}$ (Stuber et al. 1982), whereas juvenile and adult pike prefer temperatures ranging from $19-21{ }^{\circ} \mathrm{C}$ (Casselman 1995). Although detailed information exists on the thermal optimas of both largemouth bass and northern pike (see Casselman 1978; Casselman 1996; Strawn 1961; Brown et al. 2009), information derived from wild fish in the Great Lakes is relatively absent from the literature and we are unaware of any studies in which they have been explicitly compared within the same waterbody.

The purpose of this paper was to compare the thermal biology and depth use of largemouth bass (Micropterus salmoides) and northern pike (Esox lucius) present in the Toronto Harbour. Specifically I sought out to 1) determine the temperature and depth use for both species of fish on a seasonal basis, 2) determine if there is evidence of thermoregulation for either species by combining telemetry data on the body temperature of individual fish and thermal data from the surrounding ambient environment, and 3) determine how temperature and depth use are influenced by biotic and abiotic factors (e.g. size, location, time-of-year).

\subsection{Methods}

\section{Study Site and Fish Collection}


This study took place in Toronto Harbour, separated from Lake Ontario by the Toronto Islands. Toronto Harbour is often described as being two separate harbours: the Inner Harbour, which is defined by the area of water enclosed by the Toronto Islands, and the Outer Harbour, which is defined by the area of water enclosed by Tommy Thompson Park (see Fig. 3.8.1). Adult northern pike and largemouth bass were caught using boatmounted electrofishing gear (Smith-Root electrofishing model SR 18.EH; 250V and 7A for intervals of $\sim 1000$ seconds) at a number of locations including the Toronto Islands, Embayment C, Cell 3, and Cell 2 (See Fig. 3.8.1). Fish selected for tagging were retained in a flow-through livewell for 1 to 3 hours prior to tagging. As of July of 2013, 83 largemouth bass and 74 northern pike were implanted with acoustic transmitters (V9TP, $9 \mathrm{~mm}$ dia. $\times 39 \mathrm{~mm}, 4.6 \mathrm{~g}$, accuracy $= \pm 0.5^{\circ} \mathrm{C}$ and $\pm 2.5 \mathrm{~m}$, resolution $= \pm 0.15^{\circ} \mathrm{C}$ and $\pm 0.22 \mathrm{~m}$; V13TP, $13 \mathrm{~mm}$ dia. $\times 45 \mathrm{~mm}, 12 \mathrm{~g}$, accuracy $= \pm 0.5{ }^{\circ} \mathrm{C}$ and $\pm 2.5 \mathrm{~m}$, resolution $= \pm 0.15{ }^{\circ} \mathrm{C}$ and $\pm 0.22 \mathrm{~m}$; Vemco, Halifax, Nova Scotia) capable of measuring depth and temperature. Acoustic transmitters were set to emit a tag-specific code (at $69 \mathrm{kHz}$ ) at intervals between 1.5 and 2.5 minutes to reduce possible code collisions.

\section{Fish Tagging}

Prior to surgery, individual largemouth bass and northern pike were transferred from a holding tank and anesthetized using either a portable electroanesthesia system (PES; Smith-Root, Vancouver, Washington) operating at $35 \mathrm{~V}$ pulsed direct currents or by using a 60 ppm clove oil bath (emulsified in ETOH) until stage-4 anesthesia was achieved. Despite evidence of high survivorship of northern pike with respect to electroanesthesia (Walker et al. 1994), preliminary observations by Veilleux (2014) revealed 6 of 18 
northern pike tagged in 2011 using the PES unit died within the first month after being released, consequentially resulting in all further tagging activities for that species to be done using clove oil. Electroanesthesia using pulsed direct current is known to result in immediate induction, quick recovery, and high survival for many species (Vandergoot et al. 2011; Rous et al. 2015) including largemouth bass. Treatments of 3 seconds induced stage-4 anesthesia for several minutes, allowing sufficient time for surgical implantation of the acoustic transmitters. All surgical procedures followed guidelines outlined by Cooke et al. (2011). While sedated, fish were placed on a v-shaped surgical table, lined with soft, non-slip rubberized material. A constant flow of water was pumped across each individual's gills to provide oxygen with a recirculating pump. All surgical tools were cleaned with povidone iodine and rinsed with deionized water before surgery; transmitters were similarly disinfected prior to being implanted. A small incision (1-3 $\mathrm{cm}$ ) was made along the ventral side of each fish, posterior to the pelvic girdle for largemouth bass and anterior to the pelvic girdle for northern pike. Each tag was then placed into the coelom and incisions were closed with absorbable monofilament sutures (PDS-II, 3-0, Ethicon, Somerville, NJ). Several experienced surgeons implanted all transmitters to reduce variation in fish survival and recovery; average surgery time was 180 seconds, however some surgeries lasted upwards of 660 seconds in attempts to determine the sex of individuals. After surgery, fish were returned to holding tanks to recover for a period of approximately 30 - 120 minutes. Following this recovery period, individuals were released at their respected capture locations.

\section{Receiver Configuration}


For the purposes of this study, acoustic arrays were used to evaluate the thermal ecology and habitat use of northern pike and largemouth bass in the Toronto Harbour. In general, receiver placement was determined using previous known techniques to maximimize fish detection. Such methods included the use of curtain arrays transition points in order to detect any fish leaving or returning into the system, and over-lapping receiver placement to maximize the detection of fish within our system. Although we originlly planned on having the entire harbour covered by an over-lapping receiver array, the cost associated with a high number of receivers and complications with high boat traffic in this area required receivers be placed only in key areas of interest. As such, receivers $(69 \mathrm{kHz}$ VR2W, Vemco) were placed at the following locations: Cell 1, Cell 2, Cell 3, Embayment A, Embayment B, Embayment C, Embayment D, the Toronto Islands, Western Gap, Eastern Gap, Jarvis Slip, Parliament Slip, Spadina Slip, Fire Dock, and the Outer Harbour Channel, which connects the Outer Harbour to Lake Ontario (Fig. 3.8.1). Receivers were also placed in areas recognized to be overwintering aggregation sites for largemouth bass and northern pike to collect temperature and depth data throughout the winter months. In total, up to 93 receviers were deployed in the Toronto Harbour during the study period (see Fig 3.8.1).

A variety of deployment methods were used to overcome the challenges associated with having acoustic receivers in the Toronto Harbour (i.e. boat traffic, ice flows, etc). Stations located in shallower waters were typically anchored to the bottom using a large cement block (60 $\mathrm{cm}$ X $60 \mathrm{~cm}$ X $10 \mathrm{~cm}$ ), embedded with a PVC pipe large enough to contain the receiver. The use of these cement blocks proved to be ideal as they were light enough to be maneuvered by hand, however heavy enough to resist movements caused by currents 
and impede vandals. Stations were either tethered to shore using aircraft cable (coated high tensile steel cable) connected a t-bar hidden in brush, or by tethering the station to a nearby retaining wall, out of reach of pedestrians. Receivers placed offshore in relatively shallow waters $(5-10 \mathrm{~m})$ were attached to either mooring buoys right below the surface of the water or anchored to the substrate and coupled with a float that was deep enough under the surface of the water to avoid boat traffic, but shallow enough to be seen and recovered. Lastly, receivers that were placed in deep offshore waters (typically depths $>$ $10 \mathrm{~m}$ ) were anchored using two sewer grates connected by a rope. Retrieval of these stations required the use of a grapple and mechanical winch as these stations weighed upwards of $60 \mathrm{~kg}$. GPS coordinates of each receiver were taken at the time of deployment to facilitate station retrieval. Despite the relatively long battery life of VR2W receivers, downloads of receiver data occurred at relatively frequent intervals (once in the spring and once in the fall) and batteries were changed every 12 months to avoid complications with potential data gaps caused by dead batteries or lost receivers.

\section{Water temperature measurements}

We deployed a large array of over 200 individual thermistor loggers (benthic and subsurface) during the periods April - November in 2012 and 2013 and continuing in 2014. In addition, the water column stratification was captured by several long thermistor chains deployed in the Inner Harbour slips, and several short thermistor chains deployed in the benthic zone on the longitudinal transect of the Outer Harbour. The thermistors on the chains were placed at $1 \mathrm{~m}$ intervals on ropes, which were kept vertical by submerged buoys. All the thermistors used were time-synchronized Onset HOBO U22 Water Temp Pro V2, and recorded the temperature every $10 \mathrm{~min}$, with an accuracy of $\pm 0.1^{\circ} \mathrm{C}$, and an 
annual drift under $0.1^{\circ} \mathrm{C}$. The navigation restrictions in the Inner Harbour prevented us from deploying thermistors in its centre; therefore, in order to understand if its spatial temperature variability is significant, we sampled the entire basin with an RBR XR-620 Conductivity, Temperature, and Depth (CTD) sonde. Furthermore, the temperature variability in the nearshore of Lake Ontario was recorded by long thermistor chain, using 24 Onset HOBO U22 Water Temp Pro V2 loggers, arranged from the bottom up to $3 \mathrm{~m}$ beneath the surface, at $1 \mathrm{~m}$ intervals. All the thermistor loggers from Carleton University, University of Toronto and TRCA were tested in laboratory conditions before deployment. In a companion study, Hlevca et al. (In Press) provide detailed information about the temperature and velocity measurements in the various zones of the harbour.

\section{Data Management and Analysis}

All data were downloaded at two separate events each year, usually once in the spring and once in the summer. Data were imported into a Microsoft Access database and filtering system, which allowed for the extraction of specific data (e.g. detections of northern pike and largemouth bass) and the ability to remove erroneous detections by identifying detections that appeared to be logically impossible (e.g. a fish being detected at two stations at the same time, detections where fish appear to move a seemingly impossible distance given the time frame of detections). Data for pike and bass were then extracted from the database, which contained all detections up to November 2013. To test for seasonal differences in thermal and depth experiences of largemouth bass and northern pike in in the Toronto Harbour, t-tests were performed on average temperatures and depths for each fish each season. We separated seasons by classifying spring to correspond to dates between March $1^{\text {st }}$ and May $31^{\text {st; }}$; summer to correspond to dates 
between June $1^{\text {st }}$ and August $31^{\text {st }}$; fall to correspond to dates between September $1^{\text {st }}$ and November $30^{\text {th }}$; and winter to correspond to dates between December $1^{\text {st }}$ and February $28^{\text {th }}$. Data was compiled by calculating daily average temperatures for each fish. As a result of variation in fish mortality and battery life of the acoustic tags, there was an imbalance in the number of observations for each fish. We used a similar method as Baird and Krueger (2011), to determine whether there was any evidence of thermoregulation in the area. Body temperatures for fish were first linked to station temperatures corresponding to the dates of detection. Body temperatures were then plotted against water temperatures, and the differences between the two were calculated for each species.

Data were then examined for outliers, collinearity, and relationships between the response and explanatory variables using Cleveland dotplots, scatterplots, and conditional box and whisker plots. The response variables, depth and temperature, were $\log _{e}$ transformed and analyzed using generalized linear mixed models (GLMM) where individual ID was treated as a random effect. Models were fitted using restricted maximum likelihood and the response variables and model residuals assumed to follow a Gaussian distribution. Explanatory variables included species (pike and bass), season (categorical), and body size (categorical: based on quartiles for each species). All model terms, including the random effect, were evaluated using AIC model selection (Akaike 1998). To identify the factors that best explained the fish depth and temperature, two sets of candidate models ( $\mathrm{n}=5$; see Table 3.7 .10$)$ were a priori hypothesized and compared using second-order AIC (Mazerolle 2015). GLMM fit was further evaluated using marginal (fixed effects) and conditional (random effects) $\mathrm{R}^{2}$ (Nakagawa and Schielzeth 
2012). Due to heterogeneity of variance among seasons, both sets of modes were further fitted with a variance structure to allow residual variance to depend on season (Zuur et al. 2009). All candidate models were validated by plotting the normalized residuals against the fitted values and each covariate. Data exploration and analyses were carried out in the R statistical environment (R Core Development Team, 2014).

\subsection{Results}

In total, 157 individuals were tagged with either Vemco V9TP or V13TP acoustic telemetry tags. Of those 157 individuals, 83 were largemouth bass and 74 were northern pike, all captured from various locations in the Toronto Harbour (See Table 3.7.1 for summary information).

\section{Harbour water temperature}

Temperatures in the Toronto Harbour appear to be highly variable throughout the year (Fig. 3.8.2) as some locations tend to be more influenced by colder lake temperatures (e.g. outer harbour, and the embayments), while others appear to be more sheltered (e.g. Toronto Islands). Based on available data from all our stations, the highest recorded temperatures occurred typically from July through to early October. Mean water temperatures throughout the winter were observed to be $2.74{ }^{\circ} \mathrm{C}$ (with temperatures ranging from $0-24.74{ }^{\circ} \mathrm{C}$ ), $6.94{ }^{\circ} \mathrm{C}$ in the spring (with temperatures ranging from $0.65-$ $25.79{ }^{\circ} \mathrm{C}$ ), $17.90{ }^{\circ} \mathrm{C}$ in the summer (with temperatures ranging from $4.76-30.14{ }^{\circ} \mathrm{C}$ ), and $11.58{ }^{\circ} \mathrm{C}$ in the fall (with temperatures ranging between $0.98-27.57^{\circ} \mathrm{C}$ ). Overall, the mean water temperature of the Toronto harbour was $8.93{ }^{\circ} \mathrm{C}$.

Thermal and depth variability between northern pike and largemouth bass 
In general, largemouth bass and northern pike had similar thermal experiences throughout the majority of the year. Throughout the spring, winter, and fall months, there appeared to be no differences in temperatures between the two species, with both species using waters of roughly $7.5{ }^{\circ} \mathrm{C}$ in the spring, $2.5{ }^{\circ} \mathrm{C}$ in the winter, and $11.5{ }^{\circ} \mathrm{C}$ in the fall (Fig. 3.8.3). However, during the summer months, largemouth bass were observed to use warmer water than northern pike (20.79 vs. $18.36{ }^{\circ} \mathrm{C}, \mathrm{P}<0.0001$, Fig 3.8.3a and Fig 3.8.3b). Pressure data revealed that northern pike and largemouth bass inhabit different depths through much of the year. In general, pike selected deeper depths than bass across all seasons (all P's $<0.0001$; see Fig. 3.8.3). Using kernal density estimations, our results revealed that pike were spending more time in temperatures that permit growth, and within their optimal thermal range, compared to largemouth bass (Fig. 3.8.4) Effects of size, location, and time-of-year on temperature and depth distributions

Filtering depth (4.8 $\mathrm{M}$ observations) and temperature data (3.05 $\mathrm{M}$ observations) into daily averages for each individual per season yielded 462 and 410 average depth and temperature values respectively. On average, largemouth bass were found at temperatures ranging from 1.39 to $24.56{ }^{\circ} \mathrm{C}$ throughout the study period with the first quartile being $6.09{ }^{\circ} \mathrm{C}$ and the third quartile being $18.60{ }^{\circ} \mathrm{C}$, while northern pike were found at temperatures ranging from 1.56 to $21.75{ }^{\circ} \mathrm{C}$ with the first quartile being $6.75{ }^{\circ} \mathrm{C}$ and the third quartile being $16.69{ }^{\circ} \mathrm{C}$. With respect to depths, largemouth bass were found at depths ranging from 0.34 to $12.35 \mathrm{~m}$ with the first quartile being $1.07 \mathrm{~m}$ and the third quartile being $3.08 \mathrm{~m}$, while northern pike were found at depths ranging from 0.17 to $12.09 \mathrm{~m}$ with the first quartile being $2.17 \mathrm{~m}$ and the third quartile being $6.08 \mathrm{~m}$ (Table 3.7.3). 
AIC indicated a random effect should be included in both models $\left(\mathrm{AIC}_{\mathrm{random}}\right.$ effect depth $=900 ; \mathrm{AIC}_{\text {intercept only }- \text { depth }}=1137 ; \mathrm{AIC}_{\text {random effect }- \text { temp }}=889 ; \mathrm{AIC}_{\text {intercept only }- \text { temp }}=$ 887). The top model (where $\triangle \mathrm{AICc}$ was $<2$ ) for depth was the global model which included all main effects and all possible interactions between season, species, and body size (M2, Table 3.7.4). The fixed and random effects in the global model of depth use explained $25.4 \%$ and $86.2 \%$ of the variance respectively. The top model for temperature included all main effects, an interaction between species and body size, and an interaction between species and season (M4, Table 3.7.4). The fixed and random effects in the top model of temperature use explained $91.5 \%$ and $92.8 \%$ of the variance respectively. Largemouth bass and northern pike depth use was highly dependent on the season and body size of the individual (Fig. 3.8.7). Although there was some overlap in depth use during spring and summer, large northern pike (857-1003 $\mathrm{mm} \mathrm{TL})$ were detected in relatively deep locations compared to medium (396-434 $\mathrm{mm} \mathrm{TL})$ and large (478-535 mm TL) sized largemouth bass (Fig. 3.8.7). Small (325-635 mm TL) northern pike depth use tended to overlap that of all sizes of largemouth bass, including the smallest individuals (271-396 mm TL). While depth use differed among body sizes and between species during winter, temperature use in the season averaged from $2.7^{\circ} \mathrm{C}(2.4,3.0,95 \% \mathrm{CI})$ and $3.1^{\circ} \mathrm{C}(2.8,3.4,95 \% \mathrm{CI})$ with little variation among body sizes (Fig. 3.8.7). Only during the summer were temperature differences apparent between species and among body sizes. In summer, large northern pike were predicted to occur at an average temperature of $17.2^{\circ} \mathrm{C}(16.0,18.6,95 \% \mathrm{CI})$ whereas small to large largemouth bass occurred along a rising gradient of temperatures up to an average of $20.3^{\circ} \mathrm{C}(18.8,21.9,95 \% \mathrm{CI}$; Fig. 3.8.6). 


\section{Evidence of thermoregulation in the Toronto Harbour}

Study fish were found to occupy different areas of the Toronto Harbour during much of the year. When water temperatures were observed to be above $10{ }^{\circ} \mathrm{C}$, the average difference between harbour and fish temperatures throughout the year was found to be $0.9{ }^{\circ} \mathrm{C}$ higher than the lake for largemouth bass and $0.7{ }^{\circ} \mathrm{C}$ higher than the lake for northern pike. The maximum difference observed for largemouth bass was $13{ }^{\circ} \mathrm{C}$ higher than the harbour, and $12.6{ }^{\circ} \mathrm{C}$ higher for northern pike. Both largemouth bass and northern pike were observed to occupy temperatures similar to the harbour as the minimum observed difference was approximately $0{ }^{\circ} \mathrm{C}$, for both species. As the two species differed with respect to their thermal optima, we examined differences between body and habrour temperatures when harbour temperatures were greater then $20{ }^{\circ} \mathrm{C}$. At higher temperatures, average differences between harbour and largemouth bass temperatures was found to be $0.7{ }^{\circ} \mathrm{C}$ warmer than the harbour, and $0.4{ }^{\circ} \mathrm{C}$ colder than the harbour for northern pike (Fig. 3.8.5).

\subsection{Discussion}

Species-specific variability in temperature and depth use

When comparing the thermal and depth experiences of both northern pike, and largemouth bass in the Toronto Harbour, our results revealed similarities in thermal experiences for much of the year, despite the two species occupying different depths. Differences in the observed depth preferences of each species can be attributed to the habitat requirements for largemouth bass and northern pike. Largemouth bass are known to prefer shallow littoral zones, consisting of areas with widespread aquatic vegetation

and enough space to allow for over-wintering (Winter 1977; Brown et al 2009; Stuber et 
al. 1982). In Ontario, optimal habitat for largemouth bass typically consists of areas of water that are less than $6 \mathrm{~m}$ in depth, have little to no current, with a muddy or gravel substrate (Lasenby and Kerr 2000). Northern pike are characteristically found in fairly shallow and vegetated waters, usually less than $4 \mathrm{~m}$ (Casselman and Lewis 1996), but can sometimes be found in waters as deep as $12 \mathrm{~m}$ during the summer. Differences in the depth preferences of pike is known to be dependent on the life stage (Pierce 2013; Casselman and Lewis 1996) but has also been linked to the potential advantages associated with being versatile (e.g. prey, temperature, dissolved oxygen). Studies have shown that large and small northern pike differ significantly with respect to depth preferences (Chapman and Mackay 1984; Pierce et al. 2013), with larger individuals utilizing both open-water and vegetated habitats, while smaller individuals were usually limited to shallow vegetated areas only (Grim 1981; Chapman and Mackay 1984; Casselman and Lewis 1995). Therefore, it is likely that northern pike in the Toronto Harbour are utilizing both deep water (e.g. Slips, Outer and Inner Harbours) and shallow water areas (e.g. embayments, cells, and the Toronto Islands), with bass being limited to shallower areas throughout the year.

Northern pike used cooler temperatures throughout the summer months than largemouth bass. Results from our analyses suggested that differences in the thermal experiences were dependent on species, season, and body size. Species-specific differences are presumably driven by differences in the optimal thermal habitat requirements of northern pike and largemouth bass. Northern pike are a coolwater fish species and thus prefer water temperatures that are considerably cooler than largemouth bass (optimal temperature range of $19-21{ }^{\circ} \mathrm{C}$ vs. $24-30{ }^{\circ} \mathrm{C}$; Venables et al. 1978; 
Stuber et al. 1982; Casselman 1978). Small pike and bass were observed to use higher temperatures than large northern pike. Previous studies have suggested that thermal preferences for pike and bass have been linked to the ontogeny of each species (Casselman 1996). Stuber et al. (1989) have reported optimal thermal habitat of mature largemouth bass occuring at temperature ranges of $24-30{ }^{\circ} \mathrm{C}$, while juvenile bass prefer slightly warmer temperatures ranging from $27-30{ }^{\circ} \mathrm{C}$ (Strawn 1961; Brown et al. 2009). For northern pike, Casselman (1995) reported optimum temperatures ranges of $22-23{ }^{\circ} \mathrm{C}$ for young-of-the-year fish, and $19-21^{\circ} \mathrm{C}$ for mature fish. Our results are consistent with results from Pierce et al. (2013), looking at thermal habitat usage of northern pike in several Minnesota lakes, which revealed small pike (less than $71 \mathrm{~cm}$ ) generally prefer prefered warmer water and were mostly found in shallow areas consisting of heavy vegetation. Large individuals (greater than $71 \mathrm{~cm}$ ), were consistently found at temperatures around $19{ }^{\circ} \mathrm{C}$, with individuals following the thermocline into deeper waters as the summer progressed.

Extensive variation in body temperatures were observed throughout the spring, summer, and fall seasons. One possible explanation for the high variation in temperature use can be given by the thermal profiles and stratification properties of Lake Ontario and thermodynamics of Toronto Harbour (See Hlevca et al. In Press). Stratification is first established between mid-May and early July (Rodgers 1987) and continues on until late September or early October. Thus, individuals are likely experiencing large changes in water temperatures as the water warms throughout the spring, and cools during the fall. Variations throughout the summer can be explained through the frequent coastal upwelling events and internal waves (seiches, Kelvin waves and Poincaré waves) that 
occur in the area (Hlevca et al. In Press). Internal Kelvin waves are large amplitude oscillations that are initiated by atmospheric perturbances and balance the Coriolis force against a topographic boundary, such as the coastline. Kelvin waves are not dispersive. Poincaré waves are dispersive near inertial oscillations (periods slightly less than $T=2 \pi / f$, where the Coriolis Parameter $f=2 \Omega \sin \varphi, \Omega$ is the rotation rate of the Earth, and $\varphi$ is the latitude), which is a period of approximately $17.4 \mathrm{~h}$ for Lake Ontario. Internal seiches are standing waves that occur throughout periods of stratification and causes waters in the epilimnion and hypolimnion to oscillate (Lam and Schertzer 1999). Coastal upwelling occurs during periods of high offshore winds, which displaces warmer surface waters inintially in the direction of the wind and later due to the Ekman effect in the direction perpendicular to that of the wind, and results in cooler, hypolimnetic water being upwelled along shorelines (Lam and Schertzer 1999). In particular, Toronto Harbour experiences an enhanced thermocline upwelling effect (amplitudes over $11 \mathrm{~m}$ ) due to the large escarpment at the end of the Outer Harbour (Huang et al., 2010; Hlevca et al., In Press), therefore, temperature fluctuations of $10-16^{\circ} \mathrm{C}$ during a $24 \mathrm{~h}$ interval are common and can occur numerous times throughout the stratified season (Hlevca et al. In Press). In addition, the superposition of Poincaré waves (average amplitudes of $4 \mathrm{~m}$ ) may have an important modulation effect on major thermocline oscillations and increase thermal variability especially in the first half of the Outer Harbour (Hlevca et al., In Press). As such, variation in temperatures throughout the spring, summer, and fall months can be linked to the hydrodamics of the Toronto Harbour.

Thermoregulation in the Toronto Harbour 
The coolwater and warmwater habitats of the Toronto Harbour allowed both northern pike and largemouth bass to thermoregulate, permitting individuals to inhabitat temperatures close to or within their optimal ranges. Thermoregulation by both species is likely a common behaviour to benefit individuals by avoiding temperatures above their thermal limits, as they usually result in adverse effects on the physiology of fish. Temperatures exceeding optimal levels have been correlated with decreased growth rates (Kershner et al., 1999), higher metabolic costs (Clarke and Johnston, 1999), and increased natural mortality rates (Houde, 1989). Sub-optimal temperatures have also been known to limit species distribution in aquatic ecosystems (Magnusson et al. 1979). Studies on smallmouth bass has revealed that July temperatures of less than $15{ }^{\circ} \mathrm{C}$ restricted young-of-the-year bass from achieving a required body size needed to overwinter, preventing the sustainability of the species (Shuter et al. 1980). Thus, behavioural thermoregulation of largemouth bass and northern pike in the Toronto Harbour is likely an adaptive response to avoid temperatures that limit growth potential.

As water temperatures exceeded $20{ }^{\circ} \mathrm{C}$, the thermoregulation of northern pike reversed and individuals actively selected water temperatures that were cooler than the temperatures recorded at the stations where they were detected. Thus it appears that northern pike are able to actively select temperatures that fall within or close to their thermal optima in order to facilitate metabolic rates needed for foraging and growth. This is consistent with our expectations and the broader literature. When Pierce et al. (2013) evaluated the thermal habitat usage of northern pike in three different lakes, they observed pike following the thermocline into deeper waters and occupying temperatures lower then expected based on previous knowledge of thermal optimas. 
The thermoregulation of largemouth bass differed from northern pike as individuals were consistently found at temperatures higher than the water temperatures of stations they were detected at. This is likely the result of bass preferring higher water temperatures than northern pike, and because water temperatures rarely surpassed the thermal limits of bass. Optimal thermal ranges for largemouth bass have been determined to be between $24-30{ }^{\circ} \mathrm{C}$ for mature individuals. Throughout the harbour it was uncommon for water temperatures to exceed $25{ }^{\circ} \mathrm{C}$ during the summer months (see Fig. 3.8.2), other than embayment $\mathrm{D}$, which was isolated from the rest of the system and emptied of fish. Largemouth bass were consequently more likely to actively seek out areas of higher water temperatures as the thermal habitat of the Toronto Harbour was only capable of supporting the growth of bass for a relatively short period of time (see Fig. 3.8.4), and very rarely reached optimal temperatures.

\section{Conclusions and management implications}

The results from the study indicate that the thermal experiences and depth preferences of northern pike and largemouth bass are dependent on a specific set of factors (i.e. species, total length, and time of year), and that the available habitat was thermally hetereogenous, allowing both northern pike and largemouth bass to effectively thermoregulate as water temperatures increased. As temperatures increased above $10{ }^{\circ} \mathrm{C}$, both northern pike and largemouth bass were able to thermoregulate such that body temperatures of individuals were higher than the water temperatures of the stations at which they were detected at, with the exception of pike having lower body temperatures when station temperatures exceeded $20{ }^{\circ} \mathrm{C}$. Results presented here hold significant value to the conservation and management plans of largemouth bass and northern pike in the 
Toronto Harbour. Currently, the Toronto Waterfront Aquatic Habitat Restoration Strategy (TWAHRS) is working to restore the aquatic habitat present in the Toronto Harbour. Aquatic habitat has been restored in Spadina, Fire Dock, Rees, and Simcoe slips, as well as Tommy Thompson Park and Lake Ontario Park, and future plans include the restoration of the Lower Don Lands. Construction on these areas is therefore ongoing throughout much of the year, and can have a negative impact on fish communities present in areas being restored. Information presented here may therefore help managers with future enhancement projects by altering construction schedules that are being used to restore these critical environments, such that the construction results in fewer disturbances of fish inhabiting the area. In general, these data will support more effective habitat management (protection and restoration) and development of more robust habitat models. 


\subsection{Acknowledgements}

We thank the Toronto and Region Conservation Authority employees that have helped with field work (Brian Graham, Adam Weir, Pete, Ross, Brad). Maxime Veilleux and Andrew Rous from Carleton University assisted with fish tagging. We also thank Todd Howell at Ministry of Environment and Climate Change for helping deploying the thermistor chain in Lake Ontario and to the Department of Fisheries and Oceans Canada for providing some of the thermistors. Funding for this research was provided by the Natural Sciences and Engineering Research Council of Canada (NSERC) in the form of an NSERC Strategic Grant to Cooke and Wells and Discovery Grants to Cooke and Wells. Cooke is further supported by the Canada Research Chairs program. We also acknowledge the support of Environment Canada and particularly appreciate the efforts of Laud Matos to secure long-term funding for this work. 


\subsection{Tables}

Table 3.7.6: Summary of physical attributes (e.g., sex, length, weight) of tagged largemouth bass and northern pike in the Toronto Harbour as of January 2014. In total 83 largemouth bass and 74 northern pike of various sizes were caught and tagged with either Vemco V9TP or V13TP acoustic tags.

\begin{tabular}{ccccccc}
\hline & \multicolumn{3}{c}{ Largemouth Bass } & \multicolumn{3}{c}{ Northern Pike } \\
& M & $\mathbf{F}$ & $\mathbf{U}$ & $\mathbf{M}$ & $\mathbf{F}$ & $\mathbf{U}$ \\
\hline Total & 12 & 21 & 50 & 12 & 22 & 40 \\
Length (mm) & 401.08 & 466.90 & 382.44 & 655.17 & 798.41 & 729.03 \\
STD & 64.80 & 40.08 & 110.94 & 99.33 & 104.10 & 163.86 \\
SE & 5.40 & 1.91 & 2.22 & 8.28 & 4.73 & 4.10 \\
Weight (g) & 1139.67 & 1906.48 & 1190.60 & 1855.67 & 3373.24 & 1938.00 \\
STD & 555.04 & 526.55 & 773.57 & 791.24 & 1384.30 & 1252.33 \\
SE & 46.25 & 25.07 & 15.47 & 65.94 & 65.92 & 62.62 \\
\hline
\end{tabular}


Table 3.7.7: Summary of the average seasonal temperatures $\left({ }^{\circ} \mathrm{C}\right)$ and depths $(\mathrm{m})$ of largemouth bass and northern pike recorded in the Toronto Harbour from April 2011 through to January 2014. N represents the total number of observation for each species, $\mathrm{SD}$ represents the standard deviation, and SE represents the standard error.

\begin{tabular}{|c|c|c|c|c|c|c|c|c|}
\hline & \multicolumn{4}{|c|}{ Largemouth Bass } & \multicolumn{4}{|c|}{ Northern Pike } \\
\hline & Fall & Spring & Summer & Winter & Fall & Spring & Summer & Winter \\
\hline \multicolumn{9}{|c|}{ Temperature Preferences (C) } \\
\hline $\mathrm{N}$ & 97436 & 76404 & 55938 & 117394 & 110579 & 91073 & 54511 & 84648 \\
\hline Mean & 11 & 7. & 20.79 & 2.45 & 11.21 & 7.65 & 18.36 & 2.67 \\
\hline SD & 4.93 & 4.89 & 3.76 & 1.11 & 4.21 & 4.23 & 3.11 & 1.39 \\
\hline SE & 0.016 & 0.018 & 0.016 & 0.0032 & 0.013 & 0.014 & 0.013 & 0.0045 \\
\hline \multicolumn{9}{|c|}{ Depth Preferences (m) } \\
\hline $\mathrm{N}$ & 155824 & 130339 & 87761 & 176865 & 155372 & 160511 & 109785 & 133481 \\
\hline Mean & 2.13 & 2.01 & 1.37 & 3.17 & 4.28 & 3.60 & 2.32 & 5.05 \\
\hline SD & 2.03 & 2.02 & 2.23 & 1.79 & 3.2 & 2.68 & 2.25 & 2.77 \\
\hline SE & 0.0051 & 0.0056 & 0.0075 & 0.0043 & 0.0082 & 0.0067 & 0.0068 & 0.0076 \\
\hline
\end{tabular}


Table 3.7.8: Summary statistics calculated from data on the depths and temperatures largemouth bass and northern pike were observed at in the Toronto Harbour, Toronto, Ontario, Canada. Included is the average minimums, $1^{\text {st }}$ quartile, median, $3^{\text {rd }}$ quartile, and average maximums.

\begin{tabular}{ccccc}
\hline & \multicolumn{2}{c}{ Temperature Statistics } & \multicolumn{2}{c}{ Depth Statistics } \\
\hline & Largemouth Bass & Northern Pike & Largemouth Bass & Northern Pike \\
\hline Min & 1.39 & 1.56 & 0.34 & 0.17 \\
$1^{\text {st }}$ Quartile & 6.09 & 6.75 & 1.07 & 2.17 \\
Median & 10.91 & 11.18 & 2.36 & 3.76 \\
$3^{\text {rd }}$ Quartile & 18.60 & 16.69 & 3.80 & 6.08 \\
Max & 24.56 & 21.75 & 12.35 & 12.09 \\
\hline
\end{tabular}


Table 3.7.9: Mean body and water temperatures $\left({ }^{\circ} \mathrm{C}\right)$ of largemouth bass and northern pike in the Toronto Harbour. Differences are between body temperature and the corresponding water temperature of the station at which each observation was detected. Negative values represent periods where the body temperature of fish was less than that of the water temperatures. Shown are observations for when water temperatures were greater then $10{ }^{\circ} \mathrm{C}$, and when water temperatures were greater than $20{ }^{\circ} \mathrm{C}$. N represents the total number of observations for each species.

\begin{tabular}{|c|c|c|c|c|c|c|c|c|c|c|}
\hline & \multicolumn{5}{|c|}{$\mathrm{Te}<10 \mathrm{C}$} & \multicolumn{5}{|c|}{$\mathrm{Te}<20 \mathrm{C}$} \\
\hline & Mean & $\mathrm{SE}$ & Min & Max & $\mathrm{N}$ & Mean & $\mathrm{SE}$ & Min & Max & $\mathrm{N}$ \\
\hline \multicolumn{11}{|c|}{ Largemouth Bass } \\
\hline Body & 17.1 & 0.022 & 6.1 & 28.3 & 48555 & 23.1 & 0.027 & 6.1 & 28.3 & 10740 \\
\hline Water & 16.3 & 0.020 & 10.0 & 26.2 & 48555 & 22.4 & 0.015 & 20.0 & 26.2 & 10740 \\
\hline Difference & 0.9 & 0.010 & 0.0012 & 13.0 & 48555 & 0.7 & 0.025 & 0.0001 & 5.4 & 10740 \\
\hline \multicolumn{11}{|c|}{ Northern Pike } \\
\hline Body & 17.2 & 0.019 & 7.1 & 27.2 & 39124 & 21.4 & 0.021 & 12.4 & 27.2 & 7857 \\
\hline Water & 16.5 & 0.019 & 10.0 & 26.2 & 39124 & 21.8 & 0.014 & 20.0 & 26.2 & 7857 \\
\hline Difference & 0.7 & 0.010 & 0.0003 & 12.6 & 39124 & -0.4 & 0.019 & 0.0009 & 4.6 & 7857 \\
\hline
\end{tabular}


Table 3.7.10: Model selection statistics from GLMMs on the Log Temperature and Log Depth of tagged Largemouth Bass and Northern Pike in the Toronto Harbour, ON. K is the number of parameters; AICc is the bias-corrected Akaike Information Criterion; $\triangle \mathrm{AICc}$ is the difference in bias-corrected AIC between a given model and the top ranked model; wAICc is the relative weight of the bias-corrected AIC; CumulWt is the cumulative Akaike weights and; L-Lik is the log-likelihood of the models; TL is the total length of a fish. All models contain individual fish ID as a random intercept. Models are fitted with an additional variance structure to allow for different variances for each stratum of Season.

\begin{tabular}{|c|c|c|c|c|c|c|c|}
\hline Model & Fixed Terms & $\mathbf{k}$ & AICc & $\triangle \mathrm{AICc}$ & wAICc & CumulWt & L-Lik \\
\hline \multicolumn{8}{|c|}{ Temperature } \\
\hline M4 & $\begin{array}{c}\text { Species + Season + Species:TL } \\
+ \text { + Species:Season }\end{array}$ & 17 & -12.6 & 0 & 0.97 & 0.97 & 24.08 \\
\hline M1 & Species + Season & 10 & -5.03 & 7.57 & 0.02 & 1 & 12.79 \\
\hline M3 & Species + Season + Species:TL & 14 & -0.58 & 12.01 & 0 & 1 & 14.82 \\
\hline M2 & Species*Season*TL & 29 & 1.2 & 13.8 & 0 & 1 & 30.69 \\
\hline M5 & $\begin{array}{c}\text { Species }+ \text { Season }+ \text { Species:TL } \\
+ \text { Season:TL }\end{array}$ & 20 & 9.96 & 22.56 & 0 & 1 & 16.1 \\
\hline \multicolumn{8}{|c|}{ Depth } \\
\hline M2 & Species*Season*TL & 29 & 746.12 & 0 & 0.93 & 0.93 & -324.04 \\
\hline M4 & $\begin{array}{c}\text { Species + Season + Species:TL } \\
+ \text { + Species:Season }\end{array}$ & 17 & 751.35 & 5.23 & 0.07 & 1 & -357.98 \\
\hline M5 & $\begin{array}{c}\text { Species }+ \text { Season }+ \text { Species:TL } \\
+ \text { Season:TL }\end{array}$ & 20 & 757.56 & 11.44 & 0 & 1 & -357.83 \\
\hline M3 & Species + Season + Species:TL & 14 & 759.73 & 13.61 & 0 & 1 & -365.39 \\
\hline M1 & Species + Season & 10 & 763.09 & 16.98 & 0 & 1 & -371.30 \\
\hline
\end{tabular}




\subsection{Figures}

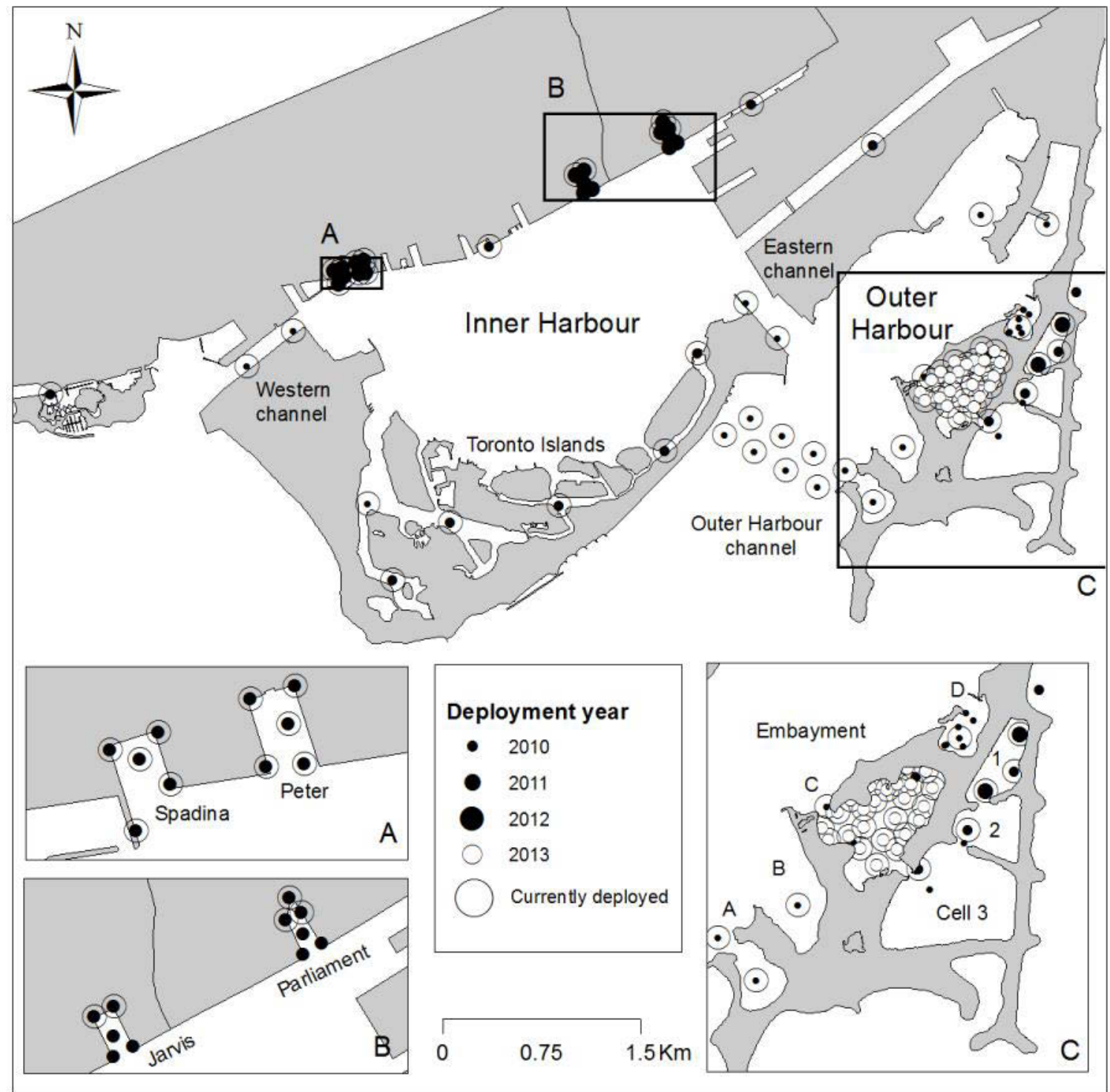

Figure 3.8.1. Map of study area and positions of acoustic receiver arrays in the Toronto Harbour. Deployment years range between 2010 and 2013, and are specified by the different sizes of filled and open circles for each station. Stations that are still currently deployed are enclosed with a larger open circle. 

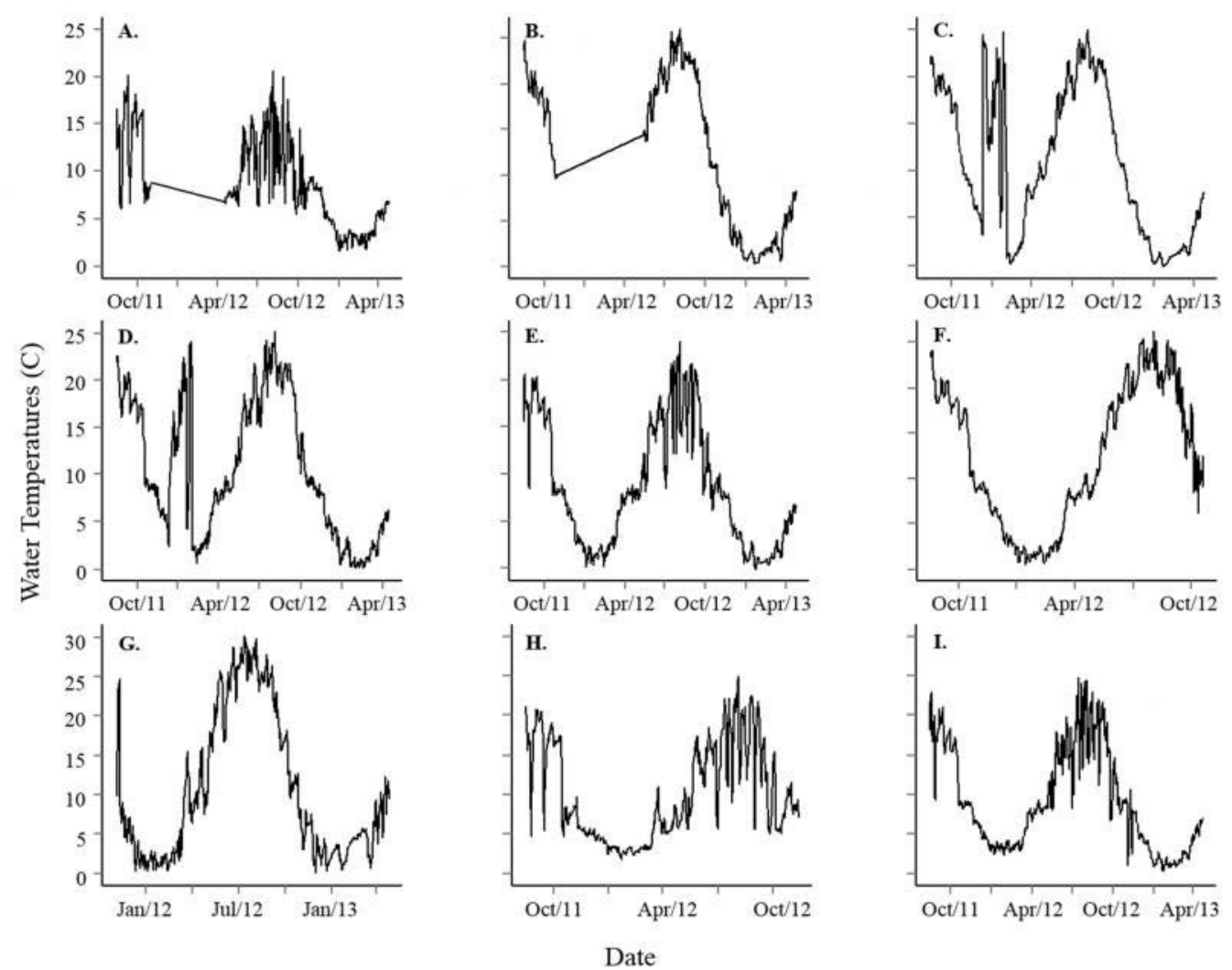

Figure 3.8.2. Water temperatures of the Toronto Harbour from October 2011 through April 2013. Temperatures were recorded every 4 hours daily by HOBO temperature loggers fixed at reciever stations. Panel A represents temperatures taken from Cherry Beach; panel B represents temperatures taken from Cell 2; Panel C represents temperatures taken from Cell 3; panel D represents temperatures taken from the Toronto Island; panel E represnts temperatures taken from Embayment $\mathrm{A}$; panel $\mathrm{F}$ represents temperatures taken from Embayment $\mathrm{C}$; panel $\mathrm{G}$ represents temperatures taken from Embayment D; panel $\mathrm{H}$ represents temperatures taken from Lake Ontario; and panel I represnts temperatures taken from Outer Harbour Marina. 


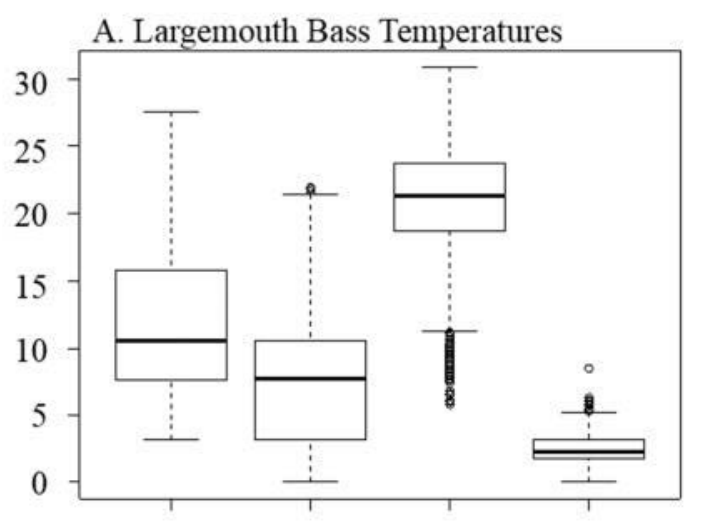

B. Northern Pike Temperatures

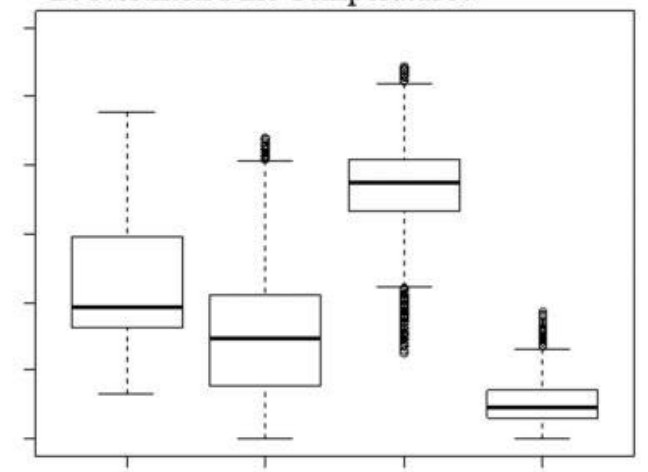

C. Largemouth Bass Depths

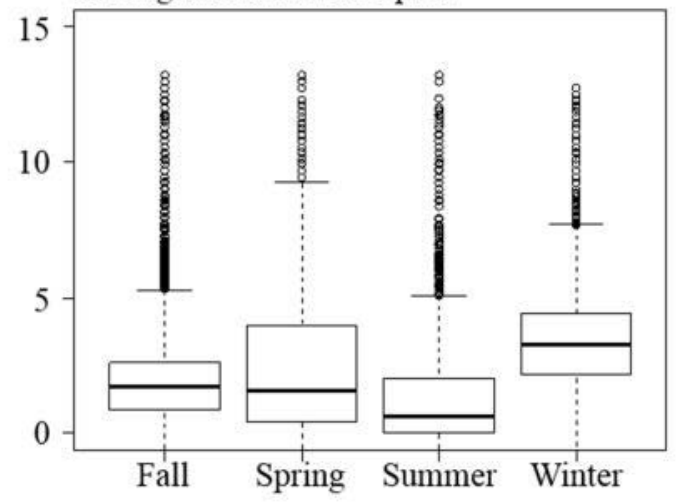

D. Northern Pike Depths

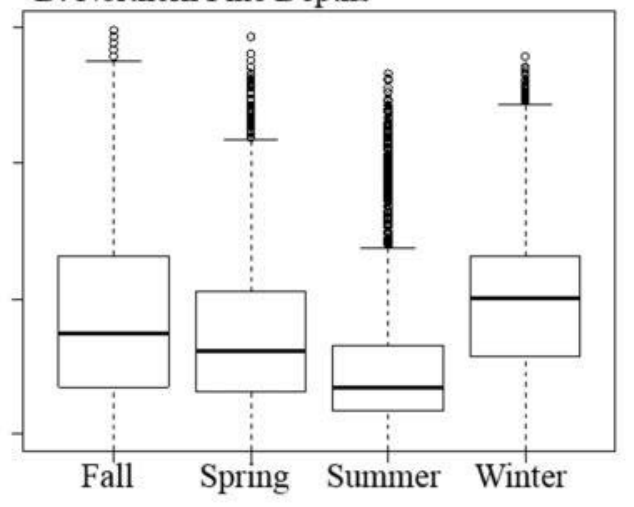

Figure 3.8.3. Seasonal thermal data and depth data for largemouth bass (panels A and C respectively) and northern pike (panels $\mathrm{B}$ and $\mathrm{D}$ respectively) present in the Toronto Harbour, Toronto, Ontario, Canada. The horizontal lines represent the means of each group. Whiskers represent the largest and smallest observations within each group that fall within $1.5 \mathrm{x}$ of the interquartile range. Observations that exceed this interquartile range are plotted as open circles. 


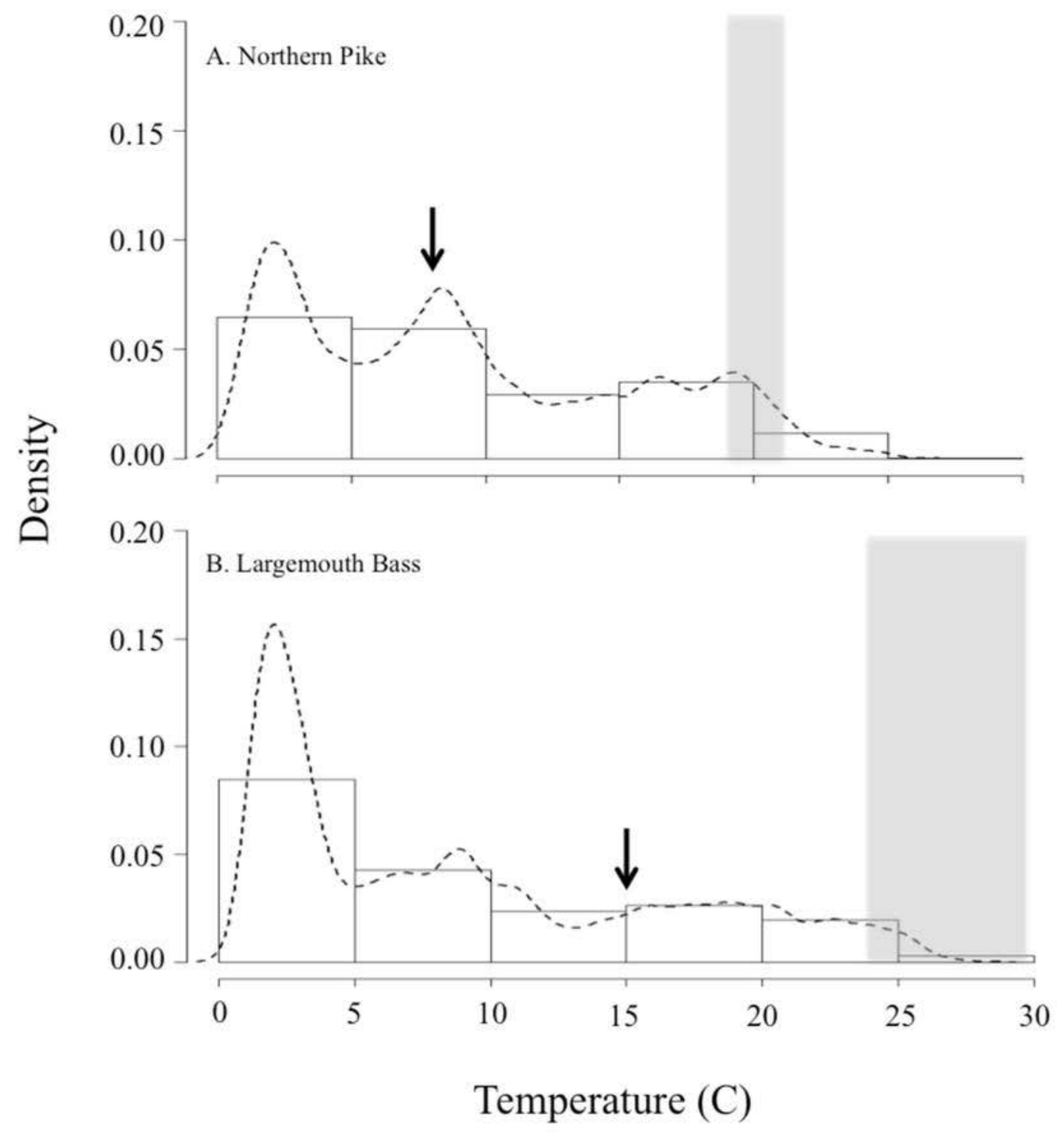

Figure 3.8.4. Relative amount of time spent within specific ranges of temperatures for tagged northern pike (A) and largemouth bass (B). Presented is a histogram paired with a kernal density estimation (dotted line), which estimates the likelihood of a random variable (e.g., Temperature) to take on a given value. Shaded regions represent optimal temperatures for growth of each species, and the arrow represents the minimum temperatures needed for growth to occur for each species. 


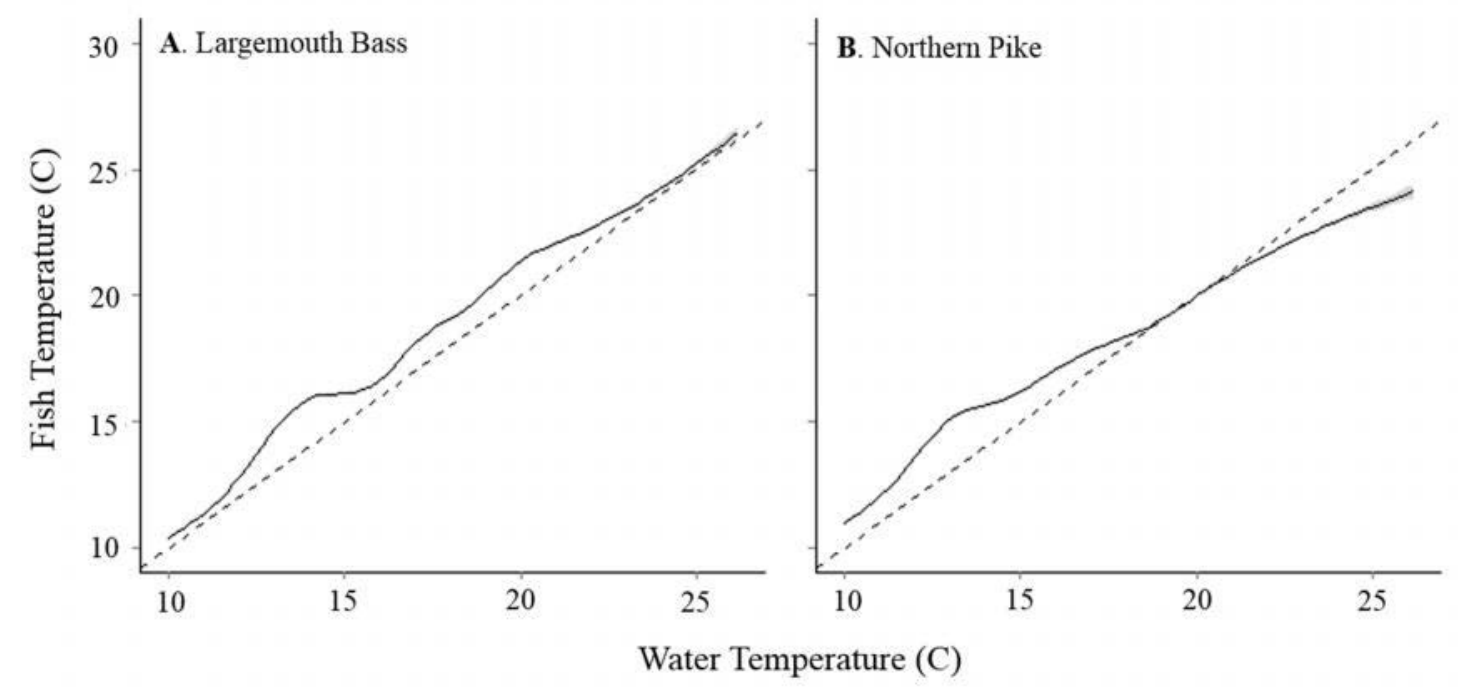

Figure 3.8.5. Largemouth bass (A) and northern pike (B) temperatures versus water temperatures in the Toronto Harbour, Toronto, Ontario, Canada. Plotted is a smoothed condition mean, and its $95 \%$ confidence intervals (shaded areas). The dashed line repsents the point at which water temperature is equal to fish temperature. 


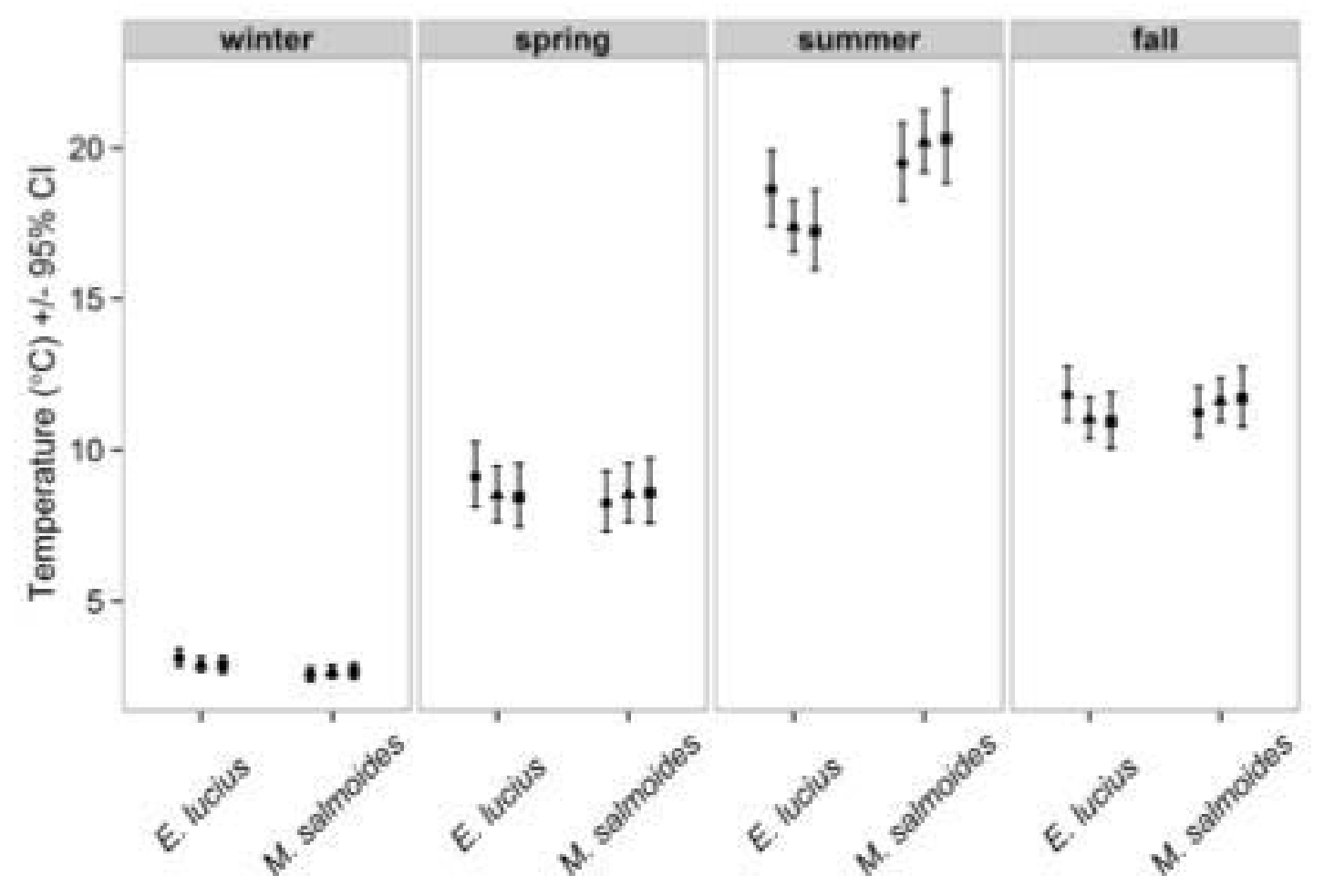

Figure 3.8.6. Mean fitted values for Northern Pike (E. lucius) and Largemouth Bass $(M$. salmoides) temperature use $\left({ }^{\circ} \mathrm{C} \pm 95 \% \mathrm{CI}\right)$ in the Toronto Harbour, Toronto, Ontario, Canada. Body sizes are illustrated as circle (small, minimum - 25\% quartile), triangle (moderate, 25\% - 75\% quartile), and square (large, 75\% - maximum) symbols. 


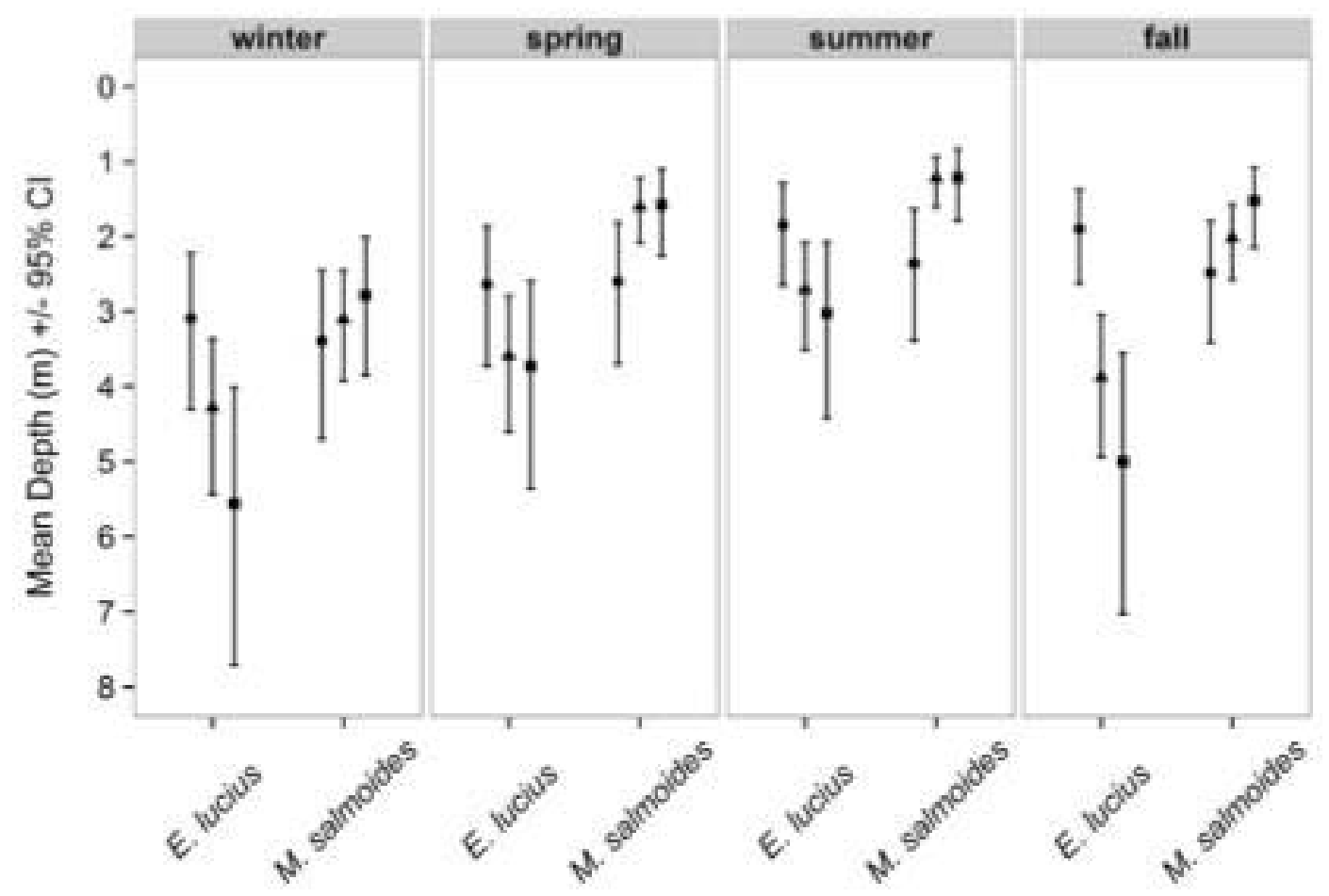

Figure 3.8.7. Mean fitted values for northern pike (E. lucius) and largemouth bass $(M$. salmoides $)$ depth use $(\mathrm{m} \pm 95 \% \mathrm{CI})$ in the Toronto Harbour, Toronto, Ontario, Canada. Body sizes are illustrated as circle (small, minimum - 25\% quartile), triangle (moderate, $25 \%-75 \%$ quartile), and square (large, $75 \%$ - maximum) symbols. 


\section{Chapter 4 - General Discussion}

The purpose of this thesis was to generate information on the thermal ecology of three popular game fish species in the Laurentian Great Lakes. In chapter 1, the thermal regimes of walleye (Sander vitreus) in Lakes Huron and Erie were determined using temperature biologgers, providing necessary data to refine sex- and lake-specific bioenergetics models of wild walleye with the goal of improving management (Hansen et al. 1993), and allowing for the future testing of ecological hypotheses. Chapter 2 focused on determining temperature and depth preferences of northern pike (Esox lucius) and largemouth bass (Micropterus salmoides) in the Toronto Harbour using biotelemetry tags that sensed temperature and pressure. Results presented here may help managers with future enhancement projects by altering construction schedules that are being used to restore aquatic environments in the Toronto Harbour, such that the construction results in fewer disturbances of fish inhabiting the area. Furthermore, these results will support more effective habitat management (protection and restoration) and development of more robust habitat models.

Although significant work has been done on the thermal biology of many fish species, little work has been conducted on wild fish in waterbodies such as the Laurentian Great Lakes. Chapters 2 and 3 satisfy this void. The future development of habitat and bioenergetic models using such data will allow managers to make lake specific decisions regarding fisheries management. Due to the nature of chapter 2, we were limited to using only one year worth of data when developing our models describing the thermal experiences of walleye in Lakes Erie and Huron. Unfortunately, annual variations in temperatures make it difficult to draw any concrete conclusions, and decisions made 
based off this data must be done cautiously as results may change between warmer or colder years. If possible, future studies should evaluate thermal data of walleye over multiple years, as well as walleye taken from different source populations. This way, models will better be able to predict thermal regimes of walleye in the Great Lakes, and will provide managers more reliable and detailed information on thermal habitat usage.

Analysis of Lake Huron walleye revealed two distinct behavioural choices that individuals face. Walleye were found to either migrate into the main basin of Lake Huron annually, or remained in Saginaw Bay, likely indicating some sort of bioenergetic tradeoff associated with either of these strategies. To remain in the basin for the duration of a year, individuals may endure suboptimal temperatures, but benefit from reduced energy budgets from not having to make the migration, as well as access to a more abundant prey base. To migrate to the main basin of Lake Huron, individuals may benefit from more optimal temperatures throughout the summer, but will have to expend more energy in making the migration to these areas of the lake. As both strategies seem to occur at the same extent, benefits from employing either strategy is likely small. This variance among individuals within Lake Huron is interesting and future studies should consider potential factors that explain why some individuals from the same population of fish are choosing to migrate into different temperature regimes (e.g. density dependent, gender based, foraging, etc).

Chapters 2 and 3 collectively describe the thermal biology of three of the more important recreational fish species in the Laurentian Great Lakes. Results from the analyses reveal some species are currently occupying temperatures within their thermal optimas for an extended period of time (e.g. walleye in Lake Huron, and northern pike in Toronto 
Harbour), while other species are occupying temperatures well below optimum levels for the duration of the year (e.g. largemouth bass in Toronto Harbour). In the near future, temperature is predicted to increase with climate change (Hayhoe et al. 2010; Magnuson et al. 1997), resulting in greater water temperatures. Magnuson et al. (1997) describes climate change to cause a number of physical and biological changes including increases in thermocline depths, decreases of dissolved oxygen below thermocline, increases in phyto- and zooplankton, increases of warm-, cool-, and cold-water habitats in deep stratified lakes (opposite for shallow stratified lakes), and changes in the growth and production of fish species. Although some work has been done on predicting potential effects of climate change on different species on fish in Lakes Michigan and Erie (Magnuson et al. 1990), future studies should consider how climate change might affect available thermal habitat for native populations of fish (i.e. walleye, northern pike, and largemouth bass) in all the Great Lakes.

In conclusion, results from my thesis explore the thermal biology of three important recreational fish species in the Great Lakes. When we considered the potential factors influencing the thermal experience of walleye in Lakes Erie and Huron, sex, size, and diel periods had no effect on thermal occupancy of adult walleye in either lake. Similarly, thermal experiences of largemouth bass and northern pike in the Toronto Harbour was found to be influenced by season, and the total length of the fish, with smaller individuals occupying greater temperatures throughout the year. Lake managers and future researchers should consider recommendations stated above and in Chapters 2 and 3 when considering the management (i.e. protection and restoration) of fish species in the Great Lakes. 


\section{References}

Akaike, H. (1998). Information theory and an extension of the maximum likelihood principle. In Selected Papers of Hirotugu Akaike, 199 - 213. Springer New York.

Bai, X., Wang, J., Schwab, D. J., Yang, Y., Luo, L., Leshkevich, G. A., and Liu, S. 2013. Modeling 1993-2008 climatology of seasonal general circulation and thermal structure in the Great Lakes using FVCOM. Ocean Model. 65: 40-63. doi:

10.1016/j.ocemod.2013.02.003.

Baird, O. E., \& Krueger, C. C. 2003. Behavioral thermoregulation of brook and rainbow trout: comparison of summer habitat use in an Adirondack River, New York. Transactions of the American Fisheries Society. 132: 1194-1206.

Baldwin, N. S., and Saalfeld, R. W. 1962. Commercial fish production in the Great Lakes, 1867-1960. No. 3, Great Lakes Fishery Commission, Ann Arbor, Michigan.

Baldwin, N. S., Saalfeld, R, W., Dochoda, M. R., Buettner, H. J., and Eshenroder, R. L. 2002. Commercial fish production in the Great Lakes 1867-2000. Great Lakes Fishery Commission, Ann Arbor, Michigan.

Barton, B. A., and Barry, T. P. 2011. Reproduction and environmental biology. Biology, management, and culture of walleye and sauger. Am. Fish. Soc. Bethesda, Maryland. pp.199-231.

Bence, J.R., and Smith, K.D. 1999. An overview of recreational fisheries of the Great Lakes. In Great Lakes fisheries and policy management: a binational perspective. Edited by W.W. Taylor and C.P. Ferreri. Michigan State University Press, East Lansing, Mich. pp. 259-306.

Bolker, B. M., Brooks, M. E., Clark, C. J., Geange, S. W., Poulsen, J. R., Stevens, M. H. H., \& White, J. S. S. 2009. Generalized linear mixed models: a practical guide for ecology and evolution. Trends in ecology \& evolution. 24: 127-135.

Brett, J. R. 1971. Energetic responses of salmon to temperature. A study of some thermal relations in the physiology and freshwater ecology of sockeye salmon (Oncorhynchus nerka). Am. Zool. 11: 99-113. doi: 10.1093/icb/11.1.99.

Brown, R. W., Ebener, M., and Gorenflo, T. 1999. Great Lakes commercial fisheries: historical overview and prognosis for the future. Great Lakes fisheries policy and management: a binational perspective. Michigan State University Press, East Lansing, Michigan.

Brown, T.G., Runciman, B., Pollard, S., and Grant, A.D.A. 2009. Biological synopsis of largemouth bass (Micropterus salmoides). Can. Manuscr. Rep. Fish. Aquat. Sci. 2884: v $+27 \mathrm{p}$.

Bulkowski, L., and Meade, J. W. 1983. Changes in phototaxis during early development of walleye. Trans. Am. Fish. Soc. 112: 445-447. doi: 10.1577/1548-

8659(1983)112<445:CIPDED>2.0.CO;2. 
Casselman, J.M. 1978. Effects of environmental factors on growth, survival, activity, and exploitation of northern pike. Am. Fish. Soc. Spec. Publ. 11: 114-128.

Casselman, J.M., and Lewis, C.A. 1996. Habitat requirements of northern pike (Esox lucius). Can. J. Fish. Aquat. Sci. 53 (Suppl.1): 161-174.

Cherry, D. S., Dickson, K. L., and Cairns Jr, J. 1975. Temperatures selected and avoided by fish at various acclimation temperatures. J. Fish. Res. Board Can. 32: 485-491. doi: 10.1139/f75-059.

Christie, G. C., and Regier, H. A. 1988. Measures of optimal thermal habitat and their relationship to yields for four commercial fish species. Can. J. Fish. Aquat. Sci. 45: 301314. doi: 10.1139/f88-036.

Clarke, A. and Johnston, N. M. 1999. Scaling of metabolic rate with body mass and temperature in teleost fish. J. Anim. Ecol. 68: 893-905. doi: 10.1046/j.13652656.1999.00337.x.

Colby, P.J., McNicol, R.E., and Ryder, R.A. 1979. Synopsis of biological data on the walleye Stizostedion v. vitreum (Mitchill 1818). Ontario Ministry of Natural Resources, Fisheries Research Section, Maple, Ontario.

Cooke S. J, Wagner, G. N., Brown, R. S., and Deters, K. A. 2011. Training considerations for the intracoelomic implantation of electronic tags in fish with a summary of common surgical errors. Rev. Fish. Biol. Fisher. 21: 11-24. doi: 10.1007/s11160-010-9184-4.

Crossman, E.J. 1996. Taxonomy and distribution. In: Pike Biology and Exploitation, Ed. J.F. Craig. pp 1-11. Chapman and Hall, London.

Desfor, G., \& Vesalon, L. 2008. Urban expansion and industrial nature: a political ecology of Toronto's port industrial district. International Journal of Urban and Regional Research. 32: 586-603.

Donaldson, M. R., Cooke, S. J., Patterson, D. A., Hinch, S. G., Robichaud, D., Hanson, K. C., Olsson, I., Crossin, G. T., English, K. K., and Farrell, A. P. 2009. Limited behavioural thermoregulation by adult upriver-migrating sockeye salmon (Oncorhynchus nerka) in the Lower Fraser River, British Columbia. Can. J. Zoo. 87: 480-490. doi: 10.1139/Z09-032

Dobiesz, N. E., and Lester, N. P. 2009. Changes in mid-summer water temperature and clarity across the Great Lakes between 1968 and 2002. J. Gt. Lakes Res. 35: 371-384. doi: 10.1016/j.jglr.2009.05.002

Eaton, J. G., and Scheller, R. M. 1996. Effects of climate warming on fish thermal habitat in streams of the United States. Limnol. Oceanogr. 41: 1109-1115.

Erickson, C. M. 1983. Age determination of Manitoban walleyes using otoliths, dorsal spines, and scales. N. Am. J. Fish. Manage. 3: 176-181. doi: 10.1577/15488659(1983)3<176:ADOMWU>2.0.CO;2.

Fielder, D. G. 2002. Sources of walleye recruitment in Saginaw Bay, Lake Huron. North Am. J. Fish. Manage. 22:1032-1040. doi: 10.1577/15488675(2002)022<1032:SOWRIS $>2.0 . \mathrm{CO} ; 2$. 
Fielder, D. G., and Baker, J. P. 2004. Strategy and options for completing the recovery of walleye in Saginaw Bay, Lake Huron. Michigan Department of Natural Resources, Fisheries Division, Ann Arbor, Michigan.

Fielder, D. G., T. L. Kolb, T. M. Goniea, D. L. Wesander, and K. S. Schrouder. 2014. Fisheries of Saginaw Bay, Lake Huron 1986-2010. Michigan Department of Natural Resources, Lansing, Michigan.

Fielder, D. G., and M. V. Thomas, 2014. Status and Trends of the Fish Community of Saginaw Bay, Lake Huron 2005-2011. Michigan Department of Natural Resources, Lansing, Michigan.

Francis, G.R., J.J. Magnuson, H.A. Regier, and D.R. Talhelm. 1979. Rehabilitating Great Lakes ecosystems. Great Lakes Fishery Commission. Tech. report no. 37.

Fry, F. E. J. 1971. The effect of environmental factors on the physiology of fish. Fish Physiol. 6: 1-98. doi: 10.1016/S1546-5098(08)60146-6.

Fuller, K., Shear, H., and Wittig, J. 1995. The Great Lakes: an environmental atlas and resource book. Great Lakes National Program Office, U.S. Environmental Protection Agency, Chicago, IL.

Gannon, J. J. 1963. River BOD abnormalities, a case study approach: the Clinton River below Pontiac, Michigan, the Tittabawassee River below Midland, Michigan. College of Engineering - Technical Report.

George, T. K., \& Boyd, D. 2007. Limitations on the development of quantitative monitoring plans to track the progress of beneficial use impairment restoration at Great Lakes areas of concern. Journal of Great Lakes Research. 33: 686-692.

Hansen, M. J., Boisclair, D., Brandt, S. B., Hewett, S. W., Kitchell, J. F., Lucas, M. C., and Ney, J. J. 1993. Applications of bioenergetics models to fish ecology and management: where do we go from here. Trans. Am. Fish. Soc. 122: 1019-1030. doi: 10.1577/1548-8659(1993)122<1019:AOBMTF>2.3.CO;2.

Hanson, P. C., Johnson, T. B., Schindler, D. E., and Kitchell, J. F. 1997. Fish Bioenergetics 3.0. University of Wisconsin Sea Grant Institute Rep. WIS-CU-T-97-001, Madison, Wisconsin.

Hartig, J. H., \& Thomas, R. L. (1988). Development of plans to restore degraded areas in the Great Lakes. Environmental Management. 12: 327-347.

Hartig, J. H., \& Vallentyne, J. R. 1989. Use of an ecosystem approach to restore degraded areas of the Great Lakes. Ambio. Stockholm. 18: 423-428.

Hartman, K. J., Kitchell, J. F. 2008. Bioenergetics Modelling: Progress since the 1992 Symposium. Trans. Am. Fish. Soc. 137: 216-223. doi: 10.1577/T07-040.1.

Harvey, B. 2009. A biological synopsis of northern pike (Esox lucius). Can. Manuscr. Rep. Fish. Aquat. Sci. 2885: v + 31 p.

Hatch, R. W., Nepszy, S. J., Muth, K. M., and Baker, C. T. 1987. Dynamics of the recovery of the western Lake Erie walleye (Stizostedium vitreum vitreum) stock. Can. J. Fish. Aquat. Sci. 44: $15-22$. 
Hayden, T. A., Holbrook, C. M., Fielder, D. G., Vandergoot, C. S., Bergstedt, R. A., Dettmers, J. M., Krueger, C. C., and Cooke, S. J. 2014. Acoustic telemetry reveals largescale migration patterns of walleye in Lake Huron. PLOS ONE. 9: e114833. doi: 10.1371/journal.pone.0114833.

Hayhoe, K., VanDorn, J., Croley, T., Schlegal, N., \& Wuebbles, D. (2010). Regional climate change projections for Chicago and the US Great Lakes. Journal of Great Lakes Research. 36: 7-21.

He, J. X., Bence, J. R., Madenjian, C. P., Pothoven, S. A., Dobiesz, N. D., Fielder, D. G., Johnson, J. E., Cottrill, A. R., Mohr, L. C., and Kroproski, S. R. 2014. Coupling agestructured stock assessment and fish bioenergetics models: a system of time-varying models for quantifying piscivory patterns during the rapid trophic shift in the main basin of Lake Huron. Can. J. Fish. Aquat. Sci. 72: 7-23.

Hokanson, K. E., and Koenst, W. M. 1986. Revised estimates of growth requirements and lethal temperature limits of juvenile walleyes. Prog. Fish. Cult. 48: 90-94. doi: 10.1577/1548-8640(1986)48<90:REOGRA $>2.0 . C O ; 2$.

Houde, E. D. 1989. Comparative growth, mortality, and energetics of marine fish larvae: temperature and implied latitudinal effects. Fish. B-NOAA. 87: 471-495.

Huang, A., Rao, Y.R., Lu, Y. 2010. Evaluation of a 3-D hydrodynamic model and atmospheric forecast forcing using observations in Lake Ontario. J of Geophys Res. 115. doi:10.1029/2009JC005601 (C02004).

Huey, R. B., and Pianka, E. R. 2007. Lizard thermal biology: do genders differ?. Am. Nat. 170: 473-478.

Huh, H. T., H. E. Calbert, and D. A. Stuiber. 1976. Effects of temperature and light on growth of yellow perch and walleye using formulated feed. Trans. Am. Fish. Soc. 105(2):254-258.

Hlevca, B., S.J. Cooke, J.D. Midwood, S.E. Doka, R. Portiss and M. Wells. In Press. Characterization of water temperature variability within a harbour connected to a large lake. Journal of Great Lakes Research. 00:000-000.

Jennings, M. J., Claussen, J. E., and Philipp, D. P. 1996. Evidence for heritable preferences for spawning habitat between two walleye populations. Trans. Am. Fish. Soc. 125, 978-982. doi: 10.1577/1548-8659(1996)125<0978:EFHPFS>2.3.CO;2.

Johnson, B. L., Smith, D. L., and Carline, R. F. 1988. Habitat preferences, survival, growth, foods, and harvests of walleyes and walleye x sanger hybrids. North Am. J. Fish. Manage. 8, 292-304. doi: 10.1577/1548-8675(1988)008<0292:HPSGFA >2.3.CO;2.

Kelso, J. R. M. 1972. Conversion, maintenance, and assimilation for walleye (Stizostedion vitreum vitreum), as affected by size, diet, and temperature. J. Fish. Res. Board Can. 29(8):1181-1192.

Kelso, J. R. M. 1976. Diel movement of walleye, Stizostedion vitreum vitreum, in West Blue Lake, Manitoba, as determined by ultrasonic tracking. J. Fish. Res. Board Can. 33: 2070-2072. doi: 10.1139/f76-255. 
Kershner, M. W., Schael, D. M., Knight, R. L., Stein, R. A., and Marschall, E. A. 1999. Modeling sources of variation for growth and predatory demand of Lake Erie walleye (Stizostedion vitreum), 1986-1995. Can. J. Fish. Aquat. Sci. 56: 527-538. doi: 10.1139/f98-193.

Kitchell, J. F., Stewart, D. J., and Weininger, D. 1977. Applications of a bioenergetics model to yellow perch (Perca flavescens) and walleye (Stizostedion vitreum vitreum). J. Fish. Res. Board Can. 34: 1910-1921. doi: 10.1139/f77-258.

Koenst, W. M., and L. L. Smith, Jr. 1976. Thermal requirements of the early life history of walleye (Stizostedion vitreum vitreum) and sauger (Stizostedion canadense). J. Fish. Res. Board Can. 33(5):1130-1136.

Koonce, J. F. Busch W.-D. N., Czapla, T. 1996. Restoration of Lake Erie: contribution of water quality and natural resource management. Can. J. Fish. Aquat. Sci. 53: 105-112.

Lam, D. C., \& Schertzer, W. M. (Eds.). 1999. Potential climate change effects on Great Lakes hydrodynamics and water quality. ASCE Publications.

Lasenby, T.A., and Kerr, S.J. 2000. Bass transfers and stocking: An annotated bibliography and literature review. Fish and Wildlife Branch, Ontario Ministry of Natural resources. Peterborough, Ontario. 207p. appendices.

Lefevre, R. 1999. "Esox lucius" (On-line), Animal Diversity Web. http://animaldiversity.ummz.umich.edu/site/accounts/information/Esox_lucius.html. Accessed: July $20^{\text {th }}, 2015$.

Madenjian, C. P. 2011. Bioenergetics in ecosystems. In Encyclopedia of fish physiology: from genome to environment. Edited by A. P. Farrell. Elsevier, Oxford. pp. 1675-1680.

Madenjian, C. P., O'Gorman, R., Bunnell, D. B., Argyle, R. L., Roseman, E. F., Warner, D. M., Stockwell, J. D., and Stapanian, M. A. 2008. Adverse effects of alewives on Laurentian Great Lakes fish communities. N. Am. J. Fish. Manage. 28: 263-282. doi: 10.1577/M07-012.1.

Magnuson, J. J., Webster, K. E., Assel, R. A., Bowser, C. J., Dillon, P. J., Eaton, J. G., ... \& Quinn, F. H. 1997. Potential effects of climate changes on aquatic systems: Laurentian Great Lakes and Precambrian Shield Region. Hydrological processes. 11: 825-871.

Magnuson, J. J., Meisner, J. D., \& Hill, D. K. 1990. Potential changes in the thermal habitat of Great Lakes fish after global climate warming. Transactions of the American Fisheries Society. 119: 254-264.

Mazerolle. M, J. 2015. AICcmodavg: Model selection and multimodel inference based on (Q)AIC(c). R package version 2.0-3. http://CRAN.R-project.org/package=AICcmodavg.

McCauley, R. W., and Read, L. A. A. 1973. Temperature selection by juvenile and adult yellow perch (Perca flavescens) acclimated to 24 C. J. Fishes. Res. Board. Can. 30: 12531255. doi: 10.1139/f73-202.

McCauley, R. W., and Huggins, N. W. 1979. Ontogenetic and non-thermal seasonal effects on thermal preferenda of fish. Am. Zoo. 19, 267-271. doi: 10.1093/icb/19.1.267. 
Melstrom, R. T., and Lupi, F. 2013. Valuing Recreational Fishing in the Great Lakes. North Am. J. Fish. Manage. 33: 1184-1193. doi: 10.1080/02755947.2013.835293.

Mitsch, W. J., \& Wang, N. 2000. Large-scale coastal wetland restoration on the Laurentian Great Lakes: determining the potential for water quality improvement. Ecological Engineering. 15: 267-282.

Morita, K., Fukuwaka, M. A., Tanimata, N., and Yamamura, O. 2010. Size dependent thermal preferences in a pelagic fish. OIKOS. 119, 1265-1272. doi: 10.1111/j.16000706.2009.18125.x.

Nakagawa, S., \& Schielzeth, H. 2013. A general and simple method for obtaining R2 from generalized linear mixed effects models. Methods in Ecology and Evolution. 4: 133-142.

Nepszy, S. J. 1977. Changes in percid populations and species interactions in Lake Erie. J. Fish. Res. Board. Can. 34: 1861 - 1868.

Newbury, R. W., and Gaboury, M. N. 1993. Stream analysis and fish habitat design: A field manual. Newbury Hydraulics Ltd., Manitoba Heritage Foundation and Manitoba Fisheries Branch, Gibsons, British Columbia.

Pearson, D., Shine, R., and Williams, A. 2003. Thermal biology of large snakes in cool climates: a radio-telemetric study of carpet pythons (Morelia spilota imbricata) in southwestern Australia. J. Therm. Biol. 28: 117-131. doi: 10.1016/S0306-4565(02)00048-7.

Petersen, J. H., and Kitchell, J. F. 2001. Climate regimes and water temperature changes in the Columbia River: bioenergetic implications for predators of juvenile salmon. Can. J. Fish. Aquat. Sci. 58: 1831-1841. doi: 10.1139/f01-111.

Pierce, R. B., Carlson, A. J., Carlson, B. M., Hudson, D., \& Staples, D. F. 2013. Depths and Thermal Habitat Used by Large versus Small Northern Pike in Three Minnesota Lakes. Transactions of the American Fisheries Society. 142: 1629-1639.

Piper, R. G., McElwain, I. B., Orme, L. E., McCraren, J. P., Fowler, L. G., and Leonard, J. R. 1982. Fish hatchery management. U.S. Fish and Wildlife Service, Washington, District of Columbia.

R Development Core Team 2012. R: a language and environment for statistical computing. R Foundation for Statistical Computing, Vienna, Austria. Available from http://www.r-project.org/.

Regier, H. A., \& Kay, J. J. 1996. An heuristic model of transformations of the aquatic ecosystems of the Great Lakes-St. Lawrence River Basin. Journal of Aquatic Ecosystem Health. 5: 3-21.

Rennie, M. D., Purchase, C. F., Lester, N., Collins, N. C., Shuter, B. J., and Abrams, P.A. 2008. Lazy males? Bioenergetic differences in energy acquisition and metabolism help to explain sexual size dimorphism in percids. J. Anim. Ecol. 77: 916-926. doi:

10.1111/j.1365-2656.2008.01412.x.

Rodgers, G. K. 1987. Time of onset of full thermal stratification in Lake Ontario in relation to lake temperatures in winter. Can. J. Fish. Aquat. Sci. 44: 2225-2229. 
Roseman, E. F., Taylor, W. W., Hayes, D. B., Fofrich Sr, J., and Knight, R. L. 2002. Evidence of walleye spawning in Maumee Bay, Lake Erie. Ohio. J. Sci. 102: 51-55.

Roseman, E.F., Knight, R.L., Wright, E., Einhouse, D., Kayle, K., Newman, K. and Hoopes, R. 2008. Ecology and International Governance of Lake Erie's Percid Fisheries. In International governance of fisheries ecosystems: learning from the past, finding solutions for the future. American Fisheries Society, Bethesda, Maryland. pp. 145-169.

Ross, M. J., and Siniff, D. B. 1982. Temperatures selected in a power plant thermal effluent by adult yellow perch (Perca flavescens) in winter. Can. J. Fish. Aquat. Sci. 2: 346-349.

Ryan, P. A., Knight, R., MacGregor, R., Towns, G., Hoopes, R., and Culligan, W. 2003. Fish-community goals and objectives for Lake Erie. Great Lakes Fishery Commission Special Publications, Ann Arbor, Michigan.

Sagonas, K., Meiri, S., Valakos, E. D., and Pafilis, P. 2013. The effect of body size on the thermoregulation of lizards on hot, dry Mediterranean islands. J. Therm. Biol. 38: 92-97. doi: 10.1016/j.jtherbio.2012.11.006.

Schertzer, W. M., Saylor, J. H., Boyce, F. M., Robertson, D. G., and Rosa, F. 1987. Seasonal thermal cycle of Lake Erie. J. Gt. Lakes Res. 13: 468-486. doi: 10.1016/S03801330(87)71667-0.

Schneider, J. C., and Leach, J. H. 1977. Walleye (Stizostedion vitreum vitreum) fluctuations in the Great Lakes and possible causes, 1800-1975. J. Fish. Res. Board Can. 34: 1878-1889. doi: 10.1139/f77-254.

Sheng, J., and Rao, Y. R. 2006. Circulation and thermal structure in Lake Huron and Georgian Bay: Application of a nested-grid hydrodynamic model. Cont. Shelf Res. 26: 1496-1518. doi: 10.1016/j.csr.2006.01.019

Snieszko, S. F. 1974. The effects of environmental stress on outbreaks of infectious diseases of fishes. J. Fish. Biol. 6: 197-208.

Spigarelli, S. A., Thommes, M. M., \& Beitinger, T. L. 1977. The influence of body weight on heating and cooling of selected Lake Michigan fishes. Comparative Biochemistry and Physiology Part A: Physiology. 56: 51-57.

Sproule-Jones, M. 2002. Restoration of the Great Lakes: promises, practices, performances. UBC Press (University of British Columbia).

Strange, R. M., and Stepien, C. A. 2007. Genetic divergence and connectivity among river and reef spawning groups of walleye (Sander vitreus vitreus) in Lake Erie. Can. J. Fish. Aquat. Sci. 64: 437-448. doi: 10.1139/f07-022.

Strawn, K. 1961. Growth of largemouth bass fry at various temperatures. Trans. Am. Fish. Soc. 90: 334-335.

Stuber, R.J., Geghart, G., and Maughan, O.E. 1982. Habitat suitability suitability index models: Largemouth bass. U.S. Dept Int. Fish Wild. Serv. FWS/OBS-82/10.16. 32p.

Swales, S. 1989. The use of instream habitat improvement methodology in mitigating the adverse effects of river regulation on fisheries. In Alternatives in regulated river 
management. Edited by J. A. Gore and G. E. Petts. CRC Press, Boca Raton, Florida. pp. 185-208.

Tang, X. L., Yue, F., He, J. Z., Wang, N. B., Ma, M., Mo, J. R., and Chen, Q. 2013.

Ontogenetic and sexual differences of thermal biology and locomotor performance in a lacertid lizard, Eremias multiocellata. Zool. 116: 331-335. doi: 10.1016/j.zool.2013.08.006.

Tsehaye, I., Jones, M. L., Bence, J. R., Brenden, T. O., Madenjian, C. P., and Warner, D. M. 2014. A multispecies statistical age-structured model to assess predator-prey balance: application to an intensively managed Lake Michigan pelagic fish community. Can. J. Fish. Aquat. Sci. 71: 627-644. doi: 10.1139/cjfas-2013-0313.

Vandergoot, C. S., Murchie, K. J., Cooke, S. J., Dettmers, J. M., Bergstedt, R. A., and Fielder, D. G. 2011. Evaluation of two forms of electroanesthesia and carbon dioxide for short-term anesthesia in walleye. North Am. J. Fish. Manage. 31: 914-922. doi: 10.1080/02755947.2011.629717.

Venables, B.J., Fitzpatrick, L.D., and Pearson, W.D. 1978. Laboratory measurement of preferred body temperature of adult largemouth bass (Micropterus salmoides). Hydrobiol. 58: 33-36.

Wang, H., Cook, H. A., Einhouse, D. W., Haas, R. C., Johnson, T. B., Kenyon, R., Locke, B., and Turner, M.W. 2007. Movement of walleye in lakes Erie and St. Clair inferred from tag return and fisheries data. Trans. Am. Fish. Soc. 136: 539-551.

Wickson, T. 2002. Reflections of Toronto Harbour: 200 years of port activity and waterfront development. Toronto Port Authority.

Winter, J.D. 1977. Summer home range movements and habitat use by four largemouth bass in Mary Lake, Minnesota. Trans. Am. Fish. Soc. 89: 323-330.

Wood, S. 2006. Generalized additive models: an introduction with R. CRC press, Boca Raton, Florida.

Zuur, A. F., Ieno, E. N., Walker, N. J., Saveliev, A. A., and Smith, G. M. 2009. Mixed effects models and extensions in ecology with R. Springer, New York City, New York. 